Es wäre gewiss ein dankenswertes Unternehmen, eine Sammlung von Dramen des vorigen Jahrhunderts zu veranstalten, um an ihr übersichtlich die verschiedenen Einflüsse aufzuzeigen, welche sich auf diesem Gebiete geltend machten, durch klassische Zeugen darzulegen, wie die Dichter aus dem französischen Klassizismus and Formalismus herauswuchsen, um sich dem englischen Individualismus zu nähern; es würde sich ergeben, wie der Sturm und Drang diesem neuen Prinzipe ganz erliegt und sich dann hindurchringt, um zu einer nenen, höheren Art des Stiles zu gelangen; wie dann die spanische Romantik eingreift und so das moderne deutsche Drama zustande kommt. Besonders die kleineren Geister, welche von der Litteraturgeschichte nur kurz behandelt werden können, miussten dabei in erster Linie berücksichtigt werden, sie sind der Spiegel, in welchem wir alle diese Züge schärfer und gedrängter $\mathrm{zu}$ entdecken vermögen. Interessante Kreuzungen liessen sich dann zumal im siebenten Jahrzehnte des vorigen Säculums klarlegen, aber immer würde man die Hauptprinzipien deutlich erkennen. An Goethes Götz von Berlichingen können wir den Einfluss von Lessings Emilia Galotti nur im schwachen Abglanze bemerken, Leisewitz nimmt in seinem Julius von Tarent die Methode Lessings als selbständiger and talentierter Schüler auf, während sie Unzer in Diego und Leonore, noch mehr Sprickmann in seiner Eulalia karrikierte. Ein Kapitel jener Sammlung müsste den Titel führen 'ans 
Lessings Schule', darin nähme das Drama, welches auf den folgenden Seiten neu gedruckt wird, einen hervorragenden Platz ein.

Wir wissen, dass Lessing keineswegs leicht produzierte, dass er, nach seinem eigenen Ausdrucke, alles durch Druckwerk und Röhren aus sich heraufpressen musste. Wie sehr dies bei Leisewitz der Fall war, zeigt das Studium des Originalmanuskriptes, welches sich von seinem Julius von Tarent erhalten hat und nun zum ersten Male veröffentlicht wird. Schon die Nachrichten, welche Kutschera in seiner Monographie über unseren Dichter aus den Tagebüchern und Briefen gesammelt hat, lehren, dass Leisewitz nicht in übermächtigem Triebe gestaltete, sondern mehr einen dichterischen Reiz empfand, welchen er durch künstliche Mittel zu steigern suchte. An Shakespeare muss er sich 'echauffiren', an den Briefen seiner Braut das Feuer für eine verliebte Scene anzünden. Er hätte seinem 'Genius' keine Hymne singen können, denn unbewusstes, 'geniales' Schaffen war nicht seine Sache, mit Bewusstsein und sichtbarer Kunstabsicht bringt er sein Drama zustande. Gerade deshalb nimmt es sich unter den übrigen Produkten der jungen Dramatiker von damals so merkwürdig gereift aus, gerade deshalb aber fehlt ihm der einschmeichelnde Hauch frischer Jugendlichkeit. Es sieht etwas säuerlich altjüngferlich drein, etwas bestäubt; Patina liegt darauf.

Wenn man die steifen geradlinigen Buchstaben betrachtet, mit denen Leisewitz seine Tragödie, wie die Briefe an seine Braut malt, so denkt man unwillkürlich seiner Akten, deren Schrift kaum gleichmässiger, lkaum steifer und geradliniger ist. Man sieht, der Dichter hat seine Gefühle nicht 'hingewühlt', sie haben auf dem langen Wege 'von dem warmen Herzen in den Verstand, und vom Verstand in die Feder', wie Leisewitz einmal an seine Braut klagt, an Ursprünglichkeit verloren, was sie an Klarheit gewannen. Die Ausdrücke sind immer wie auf Schrauben gestellt, wohlerwogen und überdacht, als 
handelte es sich nicht um leidenschaftliche Ergüsse, sondern um klare juristische Distinktionen, als spräche der Advokat, der inmer fürchten muss, von seinem Gegner an einem Wörtchen gepackt zu werden. Die Anmut fehit seiner Sprache ganz, sie ist klar und einfach, und alles erweckt den Eindruck des Schlichten, freilich auch etwas des Hausbackenen. Wärme mangelt nicht, wohl aber mächtiges Feuer, es ist keine hellodernde Flamme, nur ein langsames Glimmen. Wiederholt bemerkt er in den Briefen an seine Braut, man necke ihn in Braunschweig, dass er ein kalter Bräutigam sei, und er muss eingestehen, dass der Schein den Leuten recht gebe. Selten bricht etwas wie Leidenschaft durch, dann aber steht er rasch vom Schreiben auf, um sich abzukïhlen, um auf andere Gedanken zu kommen. Auch diese Briefe sind voll Haltung, voll schöner Gedanken und ehrenwerter Gefühle, doch reissen sie nicht übermächtig hin, sondern gehen in sanftem Laufe ruhig und ebenmässig weiter, kaum hie und da aufrauschend. Diese Briefe an seine Braut lassen uns seine Natur ganz erkenmen, bestätigen jedoch alles, was wir aus seiner Schriftstellerei herauslesen.

Gerade einer solchen Natur musste Lessings Art stammverwandt erscheinen, gerade sie konnte sich leicht in Lessing einleben, ohne den Schein der Nachabmung hervorzurufen. Leisewitz holt sich nur für seine Eigenart gleichsam die Bekräftigung bei Lessing, er pfropft nicht etwas Fremdes seinem Wesen auf. Nicht schärfer könnte der Unterschied zweier Richtungen ausgesprochen werden als durch einen Vergleich zwischen dem Julius von Tarent und Klingers Zwillingen. Der Stoff ist der gleiche, bei beiden Rücksicht auf die Anforderungen der Bühne, und doch alles anders, nicht so sehr in der Darstellung als in der Natur beider Dichter begründet. Kaum glaublich erscheint es, dass beide Werke fast $\mathrm{zu}$ gleicher Zeit von Altersgenossen gedichtet worden, freilich hat der Eine rasch improvisiert, der Andere sorgsam gedrechselt und gefeilt. 
Beide waren bekanntlich im Jahre 1752 geboren, Klinger am 17. Februar als Sohn eines Frankfurter Kon. stablers und einer früheren Kammerjungfer; Johann Anton Leisewitz in Hannover am 9. Mai als Sohn eines reichen Weinhändlers, seine Mutter war eine geborene Cathrin Luise von der Veeken. Mühsam und kümmerlich verstrich Klingers Jugend, auf Umwegen über schwere Hindernisse kam er zum Gymnasium und zur Universität, während Leisewitz, wie es scheint, auf der gewöhnlichen Bahn normaler Entwickelung eines künftigen Beamten vorwärts schritt; nachdem er in Hannover das Gymnasium absolviert hatte, bezog er im Jahre 1770 die Universität Göttingen (immatrikuliert am 16. Oktober); während sich Klinger, wie man annehmen muss, nach seinem Austritt aus dem Gymnasium erst anderthalb Jahre lang das nötige Kapital erwerben musste, um am 16. April 1774 in Giessen immatrikuliert zu werden. Aber in dieser Zwischenzeit hatte Klinger mit Goethe verkehrt und Teil an den ersten genialen Erzeugnissen der neuen Litteratur genommen; auch er war in jenen poetischen Rausch geraten, welcher ansteckend auf die Jugend von ganz Deutschland wirkte. Darum versucht er sich auch sogleich in einer Reihe von dramatischen Produktionen, deren mannigfaltiger Ton auf entschiedenes Talent hindeutet; ihm wird alles zum Drama, sein eigenes Leben, wie geschichtliche Ereignisse, das gewaltigste Bedürfnis treibt ihn an, seinem inneren Sturm im Drama Luft zu verschaffen. Er steckt voll von Planen und Entwürfen, Modernstes steht neben Antikem, Ritterdrama neben dem bürgerlichen, Komödie neben Tragödie; das ist ein geniales Herausbrausen und Hervorsprudeln, der vollkommenste Gegensatz za Leisewitzens Art.

Dieser fasste schon auf der Universität den Plan zu einer grossen 'Geschichte des dreissigjährigen Krieges' auf Grund sorgfältigster Quellenstudien; für das Fach der Geschichte wird er in den Hain aufgenommen (2. Juli 1774), obwohl auch das Fach des Dramas im Bund noch un- 
besetzt war. Man betrachtete ihn demnach nicht als Dramatiker, obwohl damals bereits sein Julius von Tarent so gat wie abgeschlossen war; vielleicht wussten die Freunde noch nicht einmal davon. Voss meldet Brückner erst am 15. August: ' $\mathrm{Er}$ arbeitet jetzt an einem Trauerspiele, wovon die fertigen Scenen vortrefflich sind.' Inı Musenalmanach debutiert er zwar mit zwei poetischen Gesprächen, welche jedoch auch mehr historisch-politischer Art sind; als Bewerber um Aufnahme in den Bund schreibt er eine vaterländisch gedachte Abhandlung (Miller an Voss), welche Klopstock überschickt wird. Leisewitz, so könnte man fast sagen, war in erster Linie Historiker und erst in zweiter Dramatiker. Wir wissen zwar anch von einigen dramatischen Planen, welche ihn jetzt und später interessierten, aber mehr als ein Spielen mit den Stoffen lässt sich kaum bemerken. Er arbeitete so schwer und mïhselig, es fehlte ihm so sehr an Mut und Energie, dass er darin das völlige Widerspiel zu Klinger ist. Sein Temperament war ein merkwürdiges Gemisch von 'Grillen' und Lustigkeit, Melancholie und bizarren Einfällen. Er bringt nichts vorwärts, weil er auf die richtige Stimmang und Stunde wartet and, ehe sie sich einstellt, manches andere beginnt, bis plötzlich Stunde und Stimmung verschwunden sind. Leisewitz ist weit entfernt von jener Leidenschaft, jener inneren Glut, welche für den Dramatiker unerlässlich erscheint. Auch seinem Naturell muss es an Leidenschaft gefehlt haben. Wir hören bei ihm nicht von tollen Liebesstreichen, wie bei Klinger, seine Braut dürfte seine erste Liebe gewesen sein; ihm wäre wohl nie der Einfall gekommen, von Giessen nach Frankfurt zu reiten, nur um unter den Fenstern einer Julia zu schmachten. Er erwirbt sich allgemeine Achtung und gewinnt einen Freund, der fest und untrennbar zu ihm hält, den nur fünf Tage jüngeren Albrecht Thaer; von den Haingenossen scheint ihm nur Johann Martin Miller näher gestanden zu haben. Wir hören aber nicht, dass er auf irgend ein Mädchen Eindruck gemacht hätte, wie etwa 
Klinger auf Albertine von Grün. Freilich bätte es ihm ferne gelegen, sich mit der Neigung eines weiblichen Wesens einen Scherz zu erlauben, wie Klinger im Anfang gethan zu haben scheint. Wie korrekt sich Leisewitz benahm, wird sich noch zeigen.

Die Universitätsjahre nutzte Leisewitz, um sich als Jurist auszubilden und so für seine künftige Karriere vorzubereiten, dabei behielt er Zeit genug, seinem Lieblingsstudium, der Geschichte, zu huldigen und sich einer breiten Lektüre hinzugeben. Auch in dieser Hinsicht unterscheidet er sich von Klinger, der sein Brotstudium ziemlich vernachlässigt haben dürfte. Und wie verschieden sind doch gerade damals ihre Mittel, Leisewitz hat Geld genug, die zu einer Geschichte des siebenjährigen Krieges, welche Klopstock gerne von ihm geschrieben sähe, nöthigen Reisen anzustellen, wie Voss an Brückner berichtet. Klinger ist so arm, dass er mit Goethes Manuskript vom 'Puppentheater', wie Höpfner Nicolai meldet, 'Wucher treiben muss', 'er kann das Geld nicht lange mehr entbehren'. Gewiss also hätte Klinger mehr Ursachen gehabt, an seiner künftigen Anstellungsfähigkeit zu arbeiten. Inneren Beruf zum Juristen scheint Leisewitz ebensowenig gefühlt zu haben als Klinger, wenn er auch später seine Thätigkeit der Juristerei zuwendete; lieber wäre ihm eine Professur für Geschichte oder eine Stelle bei einer Bibliothek gewesen.

Ende September oder Anfangs Oktober 1774 verliess Leisewitz Göttingen, ohne sich von den Freunden verabschiedet zu haben, ging nach Celle, wo sich seine Eltern aufhielten, unterzog sich am 27. Oktober vor dem Oberappellationsgerichte dem Advokatenexamen und wurde zwei Tage später als Advokat zugelassen; in Hannover nahm er seinen Wohnsitz, fand aber wohl wenig Gefallen an seinem neuen Berufe: 'Er hatte keine Passion für sein Metier', wie Thaer berichtet. Allerlei Reisen, die Schlussredaktion seines Julius von Tarent und ein neues Drama 'Konradin' neben Übungen im mündlichen Vortrag mit 
Rücksicht auf einen zu erlangenden Lehrstuhl scheinen ihm Ersatz geboten zu haben. Damals muss auch ein unerfreulicher Umschwung in seinen Vermogensverhältnissen eingetreten sein, vielleicht veranlasst durch den Tod seines Vaters. Er musste suchen, 'wie die anderen Poeten, sein Boot nach der Küste des Gewinnes zu stenern'. Er entschloss sich daher, seine Tragödie zu verwerthen. Die näheren Umstände sind wiederholt erzählt.

Im Frühjahre 1775 erschien in verschiedenen öffentlichen Blättern folgende

$$
\text { Ankündig ung. }{ }^{1} \text { ) }
$$

In Betrachtung, dass unsere guten Schriftsteller bisher fast gar keine Aufmunterung gehabt haben, für das Theater zu arbeiten, als den Trieb ihres Genies, indem die unredliche Gewinnsucht der Nachdrucker nebst andern Umständen es noch beständig den deutschen Buchhändlern unmöglich machen, den Verfassern ein verhältnismässiges Honorarium $\mathrm{zu}$ accordiren, und weil wir nicht ohne Ursache glauben, dass dieses eine der stärksten Ursachen sei, warum mancher für das dramatische Fach sehr fähige Kopf lieber solche Arbeiten unternimmt, die ihm die darauf verwendete Zeit wenigstens besser vergelten, als Verleger es können; so haben wir geglaubt, es sei unsere Pflicht, nach unseren Kräften etwas beyzutragen, dass diejenigen unter unsern deutschen Genies, die nicht in solchen Glücksumständen leben, dass sie blos ihrem Triebe Raum geben können, gleichwohl einen Theil ihrer Musse der Bühne widmen dürfen, ohne zu fürchten, dass sie Zeit, Mühe und Talente ganz umsonst verschwenden möchten.

Wir erbieten uns also, für jedes Originalstück, von 3 oder 5 Acten, sei es Trauer- oder Lustspiel, dem Verfasser 20 alte Louisd'or, jedoch unter folgenden Bedin-

1) Abgedruckt in Hennebergers Jahrbuch 1, $111 \mathrm{ff}$. 
gungen ze bezahlen: Wir milssen nembich 1) ersuchen, duss das stuck von der Beschaffenheit sey, dass es a. in Ansebung seines sittlichen Inhalts af die Buhne gebracht werden durfe; das es anch b. um anfs Theater gebracht so werden, keine anserordentlich grosese Kosten an ungewohnlichen Kleidertrechten und sonstigen Decoretionen erfordere; ferwer a nicht die Zehl der agirenden Pereonen tbbersteige, die man billiger Weise anf einer dentschen Bthne erwarten kann; d. ob wir gleich Tranerspiele in Versen nicht ganz ansschliessen, so werden uns gleichwohl die in Prosa von sonst gleicher Gute viel lieber seyn.

2) Mussen wir bitten, dass man uns nicht so versteben möge, als machten wir uns verbindlich, jedes Sthck, das ons der Verfasser zuschickte, mit 100 Thlr. bezahlen zn wollen. Wir winschen durch diesen Weg mehr gute Originalsticke anf unser Thester 20 bringen. Und daher lassst sich freilich schon schliessen, dass wenn wir uns auch dramatorgische Kritiken anmassen durften, wir dennoch unter den jetzigen Umständen nicht so gar strenge seyn würden. Allein wenn ein Verfasser uns ein Stuck zuschickt, das wir ans uns anch nur bekannten Grunden nicht anffihrbar fanden, mbisste sich der Verfasser nicht farr heleidigt halten, wenn wir ihm, spätestens innerhalb 4 Wochen, sein Sttick an die uns bekannt gemachte Adresse wieder zurtickliefern.

3) Bleibt der Verfasser zwar immer Herr tber sein Menuscript und kann es nach eigenem Belieben einem Verleger verkanfen oder auf eigene Rechnnng drucken lassen, bis es, vom Tage der ersten Vorstellung an gerechnet, 6 Monate auf dem Theater gewesen. Sollte er uns aber sein Manuscript mit dem Verlagsrecht abtreten wollen, so wäre dies eine Sache, ther die wir uns besonders mit ihm einigen wurden.

4) Lassen wir es uns gern gefallen and seben 6 gewissermassen sogar lieber, wenn uns die Stücke ohne Namen der Verfasser eingesandt und nur eine sichere 
Adresse, wohin wir entweder das Stück oder das Geld remittiren sollen, bekannt gemacht werden: jedoch musste die Quittung tiber das empfangene Geld, welches gleich nach der ersten Vorstellung ansgezahlt werden soll, von dem Verfasser selbst oder von einem sichern Manne anterschrieben werden, der zugleich für den im 8. Punkte erwalnten sechsmonatlichen alleinigen Besitz Burge worde; und zwar bei Verlust der Hälfte des Honorarii. Uebrigene versprechen wir, wenn and so lange es verlangt wird, den Namen des Verfassers anfs Heiligste zu veroctrweigen.

Unter den oben angefuhrten Bedingungen erbieten wir uns, fur eine gate dentsche Übersetzang eines guten 8tucks 6 Lonisd'or oder 30 Thlr. 20 bezahlen. Jedoch wird es nothig sein, dass die Herrn Uebersetzer uns erst die stncke anreigen, welche sie tabersetzen wollen, damit uicht mehrere zugleich ein und dasselbe Stück einsenden und derjenige, welchem wir seine Uebersetzung zurtickwchicken murssten, glanben möchte (velcher Irrthom bei Originalsthcken nicht entstehen kann), wenn er abwesend erfuhre, das Sthck whre anfgeftubrt, man habe seine Uebersetzang widerrechtlich abgeschrieben, oder anch nnr zum Verbessern einer andern gebraucht: auch diunkt uns, dass vir es, ohne Tadel zu besorgen, änssern dürfen, dase es sehr angenehm sein whrde, wenn ganz fremde und sebr venig bekannte Sitten und Gebrtuche anderer Nationen mit deatschen vertanscht wurden. Wir lengnen es wicht, dase wir eine solche Verptlanzung einer sonst übrtzens getreuen Uebersetzung vorziehn wurden.

Noch bitten wir, die ofentliche Bekanntmachung dreses Unternehmens keiner andern Absicht zurnschreiben, als drmit os dedarch solche Gelehrte erfahreo mogen, die wir nicht die Whre haben za kennen, um es ihnen privatim hond za thon.

Sollte einer oder der andere Herr Verfaseer uns unter andern Bedingningen seine Arbeit tberlassen wolten, 60 wird ans dem Vorigen schon erhellen, wie geneigt wir 
sind, dramatiscbe Talente zo verehren und die fur uns angewendete Mthe nach unsern Kraften erkennen.

Hambarg den 28sten Febr. 1775.

Sophie Charlotte Ackerman. Friedrich Ladwig Schroder.

Schon 2u Ostern 1775 ist Leisewitz entschlossen, sein Drama nach Hamburg zu senden, 'um die Pramio von 100 Thalern zu verdienen'. Anfangs Mai war 6 fertig, bevor er jedoch die $\Delta$ bschrift nach Hamburg abgehen liess, bat er im Jnli seinen Freund Thaer, welcher sich in Celle als Arzt niedergelassen hatte, um sein Urteil and Ende desselben Monats anch nocb Herder. Im Angust dürte der Julius von Tarent den Weg nach Hamburg angetreten haben.

Leisewitz hatte sein Drama bereits in Göttingen begonnen and nahezu vollendet. Wir rermögen der allmählichen Entstehnng anf Grund des Originalmanuskriptes za folgen; Leisewitz schrieb nämlich sein Drama jedesfalls nach einem vorher entworfenen Scenarium, denn er greift bald diese, bald jene Scene beliebig ans dem $\mathrm{Za}$ sammenhange heraus ${ }^{1}$ ); deshalb war er auch genötigt, for jede Scene ein nenes Blatt Papier za nehmen and an Rande den Platz zu bemerken, welchen sie im Drama bekommen sollte. Dies geschah in Bruchform, so dass 1/1 hejsst: erster Akt, erste Scene. Überdies hatte Loisewitz die Gewohnheit, den Tag der Abfassang fur die meisten Scenen dabei za notieren, 80 dass wir in der Mehrzahl der Fälle genau sagen können, wann er die Scenen verfasste oder redigierte. Diese Daten hat zuerst Kutschera S. 69 Anm. 3 bekannt gemacht, leider nicht fehlerfrei. Ich gebe sie hier übersichtlich und dann die

1) Eine Folge dieser Arbeitsweise zeigt sich aber in dem mangelnden Zusammenhang einzelner Scenen, in den fehlenden Ũbergängen, was schon Eschenburg in der Allgemeinen deutschen Bibliothek tadelte. 
chronologische Reihenfolge der Scenen, soweit wir sie feststellen konnen.

I 1 den 24. Jalins 1774 im ersten Entworf, die Umarbeitung ist ondatiert.

I 2 den 29. resp. 30. Julins 1774 , dies ist wohl 80 zu versteben, dass Leisewitz am 29. begann, am 30. den Beginn veränderte und dann fortfahr, abgeschlossen den 2. September.

I 3 den 81. Julins 1774, fortgesetzt 1. Angust 1774 (Kotschera lat das dentlich in der Handschrift stehende Ang. in May verlesen und deshalb den Beginn der Arbeit so frub angesetzt. Denselben Fehler machte er $\nabla 2$, bemerkte ihn aber rechtzeitig).

I 4 undatiert.

I 5 undatiert.

I 6 den 5 . Angust 1774 begonnen, am 6. noch einmal, doch verwarf er diesen 2weiten Beginn bei der Wiederanfnahme der Arbeit and kehrte zo der ersten Fassung zurlack; die Scene wird jetzt abgeschlossen, am 12. Augast aber der Schluss erweitert and erst am 13. August der neae Schluss gefunden.

I 7 den 9. August 1774, fortgesetzt den 10. Angast.

II 1 vor d. 24. Jolins 1774. [Es kann auch heiseen 'Vor' also 'Vormittag' ?]

II 2 den 25.-30. Anguat 1774.

II 3 (Bannover?) den 18. Oktober. Die Lesung Brnnover ist kaum denkbar, man wtirde eher Sonnabend heranslesen, der 18. Oktober fiel aber in jenem Jahre nicht anf einen Sonnabend.

II 4 (zuerst als I 4 bezeichnet) undattert.

II 5 undatiert.

II 6 undatiert.

II 7 (zuerst als II 6 bezeichnet) den 29. resp. 80. Jali 1774 ( 
III 1 den 26. Julius 1774.

III 2 den 1. September, fortgesetzt den 2. September, den 3. September 1774, vollendet den 4. September.

III 3 den 6. September, fortgesetzt den 8. September.

III 4 den 12. September 1774 .

III 5 (znerst als III 4 bezeichnet) undatiert.

III 6 (zuerst als III 7 bezeichnet) den 2. August 1774 .

III 7 (zuerst als III 8 bezeichnet) im ersten Entwarf den 2. August 1774 begonnen, dann den 4 . Angust überarbeitet und fortgesetzt.

IV 1 den 19. August 1774.

IV 2 den 20. resp. 21. August 1774, fortgesetzt den 22. August und den 23. August, der Schluss fehlt in der Handschrift.

IV 3 undatiert.

IV 4 29. Julius 1774.

IV 5 undatiert.

IV 6 (zuerst als IV d[ie] I[etzte] 7 Scene bezeichnet) den 27. Julius 1774.

V 1 (in der später ganz verworfenen Fassung) den 27. Julius 1774.

V 2 den 6. August 1774 zuerst begonnen, den 7. resp. 8. August 1774 überarbeitet and fortgesetzt.

V 3 fehlt in der Handschrift.

V 4 (zuerst als V 3 bezeichnet) undatiert.

$\mathrm{V} 5$ den 8. August 1774 .

V 6 den 15. August 1774 .

$\checkmark 7$ den 15. Augast 1774.

$\mathrm{V} 8$ den 16. August.

V 9 (zuerst als $V 2$ bezeichnet) den 27. resp. 28. Jalius 1774.

Leisewitz begann also die Niederschrift, so viel wir sehen, vor dem 24. Julius 1774 mit II 1. 
24. Julius I 1 (erster Entwarf).

26. $n$ III 1 .

27. " IV $6 . \vee V 1$ (jetzt fehlend), $\nabla 9$.

28. $\pi \quad \nabla 9$.

29. $\quad$ IV 4. I 2. II 7.

30.,$\quad$ I 2. II 7 .

31. $\rightarrow \quad$ I 3 .

1. Angust I 3.

2. $"$ III 6. 7 .

4. $\rightarrow$ III 7.

5. " I 6 (erster Entwurf).

6. " I 6 (zweiter Entwurf), V 2 (erster Entwurf).

7. $\gg \mathrm{V} 2$.

8. $\pi$ V $2 . \mathrm{V} 5$.

9. $\rightarrow \quad I 7$.

10. $\quad 17$.

12. $₫ \quad I 6$.

13. "I 6 .

15. " V6. V 7 .

16. " V 8 .

19. " IV 1.

20. $\rightarrow$ IV 2.

21. $\quad$ IV 2.

22. " IV 2.

23. " IV 2 (Schluss fehlt).

25.-30. August II 2.

1. September III 2.

2. $\rightarrow$ III 2. I 2.

3. $n$ III 2 .

4. $\rightarrow \quad$ III 2 .

6. $n$ III 3 .

8. $n$ III 3.

12. $\rightarrow$ III 4.

18. Oktober (Hannover??) II 3.

Leisewitz schreibt sonach rom 24. Julius 1774 bis 12. September fast täglich an seinem Drama, ausgenommen sind die Tage: 25. Juli, 3. 11. 14. 17. 18. 24. 
31. August, 5. 7. 9. 10. 11. September, dafür tragen die Scenen I 1 (neue Fassung), 4, 5. II 4, 5, 6. III 5. IV 3, 5. V 1 (neue Fassung), 3 (fehlt in der Handschrift), 4 kein Datum. Er hat also für 23 Scenen 37 Tage gebraucht, 11 (resp. 12) Scenen tragen kein Datum und an 14 Tagen scheint die Arbeit geruht zu haben, wenn an ihnen nicht, wie das Zahlenverhältnis ergäbe, die undatierten Scenen entstanden. ${ }^{1}$ )

Im wesentlichen hat demnach Leisewitz seinen Julius von Tarent in der Zeit von Mitte Juli bis Mitte September 1774 in Göttingen vollendet, was besonders bei seiner Art zu produzieren überraschend schnell ist. Wiederholt beginnt er eine Scene, überarbeitet den Anfang, kehrt später zur verworfenen Fassung zurück, setzt sie fort, am folgenden Tage streicht er wieder, schreibt an den Rand oder auf ein neues Blatt eine neue Gestalt; oder

1) Ich habe nachträglich noch den Versuch gemacht, durch genaue Vergleichung von Papier und Schrift auch die nicht datierten Scenen chronologisch einzureihen, bin aber nur zu.Vermutungen gekommen; darnach scheint es mir, dass die Überarbeitung von I 1 auf demselben lichteren Papier und mit ähnlicher dickerer Schrift aufgezeichnet sei wie I 4 und I 5, II 4, II 5 (wenigstens ein Teil, denn es sind andere Blätter später eingelegt, sie enthalten Korrekturen), II 6 (diese drei letzteren II 4-6 sind in der Schrift untereinander ähnlicher als mit I 1. 4. 5). Ähnlich ist die Schrift in III 5 und IV 3 und auch sie erinnert mehr an I 1 als an die datierten. Am meisten Ähnlichkeit hat I 1.4.5 mit II 1, welche Scene 'vor (?) d. 24 Julius 1774' datiert ist. Wäre meine Beobachtung richtig, dann müssten wir annehmen, alle undatierten Scenen, ausgenommen V 1 in der Fassung des Druckes, seien vor dem 24. Juli 1774 gedichtet, Leisewitz habe sich erst an diesem Tage entschlossen, die Daten seinen Scenen beizuschreiben; dann aber würde sich das Datum ' 24 . Julius 1774' auf der ersten Fassung von I 1 nicht erklären lassen. Ich vermag daher mit der Beobachtung nichts anzufangen, und wenn man bedenkt, wie sehr besonders eine Kielfeder je nach dem breiteren oder spitzeren Zuschnitt die Schrift verändert, wird man skeptischer. Doch schien es mir nötig, auch dieses Mittel zur Datierung zu proben. Das Papier hat kein Wasserzeichen. 
er schliesst eine Scene: da er wieder an das Drama geht, erscheint ihm dieser Schlnss verfruht, er verwirft ihn daher, erweitert ihn und vollendet ihn erst später. Kaum eine einzige Seite findet sich ohne zahlreiche Korrekturen, welche sogleich oder jedesfalls bei Wiederaufnahme der unterbrochenen Arbeit vorgenommen wurden. Deshalb ist auch nicht anzunehmen, Leisewitz habe nur die Daten einer überarbeitenden Abschrift am Rande festgehalten, mit wenigen Ausnahmen (z. B. I 1) dürfte die erste Niederschrift vorliegen, welche zugleich die Schlussredaktion darstellt. Unzweifelhaft liess Leisewitz ans der uns vorliegenden Handschrift für den Druck eine Kopie durch fremde Hand anfertigen, der Nachweis wird weiter unten erbracht werden.

Er beginnt mit der ersten Scene des zweiten Aktes, das ist mit der Unterredung zwischen Julius und der Abtissin im Kloster, also mit einer Scene, welche durchans nicht zu den bedeutsamsten im Drama gehört. Dann dichtet er hinter einander den Beginn des ersten, dritten und fünften Aktes (I 1. III 1. V 1), was wenigstens zum Teil auffallend ist, denn die Scene der beiden wachebaltenden Soldaten (V 1) hat nur episodenhaften Charakter and die Idylle III 1 giebt nar den Hintergrund für den Fürsten Constantin. Wenn wir uns aber der beiden dramatischen Scenen im Musenalmanach erinnern: Der Besuch um Mitternacht und Die Pfandung, dann wird es uns erklärlich, waram Leisewitz gerade V 1 and III 1 zuerst in Angriff nahm; der Besuch am Mitternacht ist ebenso ein Gegenstijck zn V 1, wie Die Pfandung zu III 1. Die beiden Soldaten (V 1) erzählen in der Mitternachtsstunde eine Gespenstergeschichte : wie der verstorbene Vorgänger des Fürsten, 'ein schrecklicher Tyrann', nach seinem Tode im wilden Heere herumzog und seinen Durst ans einem Becher mit rauchendem Menschenblute stillen musste; im 'Besuch um Mitternacht' erscheint dem buhlerischen, anf seine Maitresse Gorgone wartenden Fursten als Geist: Hermann der Cherusker und donnert ibm den 'respekt- 
widrigen Ausdruck': 'Du der Tyrann von Sklaven, und Sklave einer Hure' $z \mathfrak{u}$, wir erbalten also auch eine Gespenstergeschichte, obgleich anderer Art. In dem festlichen Empfang an Constantins Geburtstage (III 1) stellt der alte Bauer Constantins Regierung in Gegensatz zu der seines Vaters: 'wir wären verhungert, wenn Sie es gemacht hätten wie Ihr Vater', und in der 'Pfandung' sehen wir die Folgen eines solchen volksverderbenden Regimentes, das zwei Lente regen eines Trunkes unglücklich macht, und, wie die Frau naiv bemerkt, 'die Fürsten können ja nie recht durstig seyn'. Beide Male der Hinweis auf die ewige Vergeltung. So muten uns die beiden Scenen im Musenalmanach wie Vorstudien zum Julius von Tarent an, dieselbe Tendenz in ihnen, wie in den beiden Auftritten III 1 und V 1. Wir verstehen also, was Leisewitz veranlasste, gerade sie zuerst zu gestalten. Es ist, als habe er das Instrument erst prüfend angeschlagen.

Dann erst wendet sich unser Dichter sogleich zu zwei entscheidenden Punkten seines Dramas, zu dem Brudermorde (IV 6) und zum Schlusse des Konfliktes im Gespräche zwischen Constantin und dem Erzbischofe (V 9). Leisewitz muss also genau vor Augen gehabt haben, wie er sein Drama gliedern wollte, die Reihenfolge der Scenen muss demnach festgestanden haben, und so bemerken wir nur wenige Schwankungen, die stärksten im dritten Akte. Hier sollte wohl Guidos Monolog keine eigene Scene bilden, sondern gleich an die Unterredung mit Julius angeschlossen werden, denn III 5, die Scene zwischen Aspermonte und Julius, wurde zuerst als 4. des dritten Aktes bezeichnet. Dann hätte jedesfalls als 5 . und 6 . Scene vor der Verwandlung etwas folgen sollen, was wir jetzt nicht mehr wissen, vielleicht ein Monolog, den Julius hielt und dessen Wiederschein in IV $2 \mathrm{zu}$ bemerken ist; aber was weiter? Das lässt sich nicht erraten. Jedesfalls führten die beiden Scenen 6 and 7 zuerst die Bezeichnung 7 und 8, die letztere im ersten Entwarfe vom 
2. August nur diese, erst bei der Überarbeitung am

4. Augast wurde aus der Acht eine Sieben gemacht.

Geringer sind die anderen Schwankungen in der

Scenenzählung. Wenn die Scene zwischen Caecilia und Portia zuerst als vierte des ersten Aktes bezeichnet wird, so kann dies nur verschrieben sein, denn jedesfalls musste I 7, die Unterredung Constantins und Caecilias, vorangehen, sonst wäre sie unverständlich. Leichter $\mathrm{zu}$ erklären ist die Bezeichnung von II 7 als II 6 , es sollte wohl Julius' Monolog keine eigene Scene bilden. Im vierten Akte sollte die letzte Scene zuerst die siebente in der Reihe sein, doch scheint auch hier nur ein Missverständnis des Dichters vorzuliegen, der sich vielleicht nicht erinnerte, wie viele Scenen dem vierten Akte zugewiesen waren, weshalb er auch schrieb: d. l. 7., das heisst gewiss: die letzte 7. Scene. Auf den Monolog des Fürsten (V 2) sollte zuerst sogleich das Gespräch zwischen Caecilia und Blanca folgen, welches deshalb als $\checkmark 3$ bezeichnet wird, wenn nicht auch hier der Monolog Blancas (V 3) mit der folgenden Unterredung zu einer Scene vereinigt werden sollte; diese Wahnsinnsscene Blancas (V 3) fehlt aber in unserem Manuskripte. Am auffallendsten ist der Umstand, dass die Schlussscene V 9 zuerst als V 2 bezeichnet wurde, was wieder nur verschrieben sein kann, denn es widerspräche der ganzen Ökonomie des Stückes, wenn man seinen Schluss schon in der zweiten Scene des letzten Aktes annäbme. Der Irrtum ist um so verständlicher, wenn man sich erinnert, dass Leisewitz V 9 am selben Tage wie V 1 begann; es veranlasste also momentane Zerstreutheit den Fehler, er wurde vielleicht sogleich verbessert.

Leisewitz hatte den Verlauf seines Stückes von Anfang an so klar vor Augen, dass er nicht die von der Geschichte gegebenen Teile zuerst bearbeitete, sondern die frei erfundenen. Überhaupt schaltete er mit der Geschichte als Dichter, der Lessings Hamburgische Dramaturgie studiert hatte. 'Der dramatische Dichter ist 
kein Geschichtschreiber', 'die Tragödie ist keine dialogirto Geschichte', solche Sātze gehörten ja wohl der allgemeinen Kenntnis. Auch Leisewitz muss sie gekannt haben, denn er scbreibt am 21. Dezember 1779 an Bibliotbekar Reinwald: 'Dje erste Idee $2 n$ meinem Stucke nahm ich ans der Geschichte des Grossherzogs Cosmus I. von Florenz and seiner Söhne Johann and Garsias.") Weil mir aber hier weder die Charaktere noch das historische Detail so ganz gefielen. schlog ich diesen Mittelweg zwischen Geschichte and Erdichtong ein. Hingegen glaubte ich die poetisch-philosophischen Sitten des Mediceischen Hofes mit Recht beyzubebalten; die Philosophie anf dem Pegasus gefiel mir'.

Bei seinen historischen Studien wurde Leisewitz, wie sich hicrans ergiebt, anf den Stoff gefthhrt, der seinem Stäcke za Grunde liegt. Kutschera, welcher sich (S. $76 \mathrm{f}$.) mit der Quellenfrage naturlich eingehend beschätigte, musste noch unbestimmt lassen, 'ans welcbem Werke Leisewitz die Kenntnis des Ereignisses entnommen'; mich hatte schon $A$. von Reumonts 'Geschichte Toscanas seit dem Ende des florentinischen Freistaats' (Gotha 1876. S. $236 \mathrm{f}$. Anm.) anf de Thon gefuhrt, auch Rieger (Klinger in der Sturm- und Drangzeit. Darmstadt 1880. S. 88 Anm.) verwies darauf und liess die betreffende Stelle daselbst abdrucken. Sie kann iu dieser Einleitung nicht entbehrt werden, weil sie uns das Rohmaterial unseres Dramas wenigstens in der einen Form zeigt.

Jacobus Augustns Thuanus erzält im zweiten Bande Historiarum sui temporis (London, Samuel Buckley, MDCCXXXIII) S. 255 f., sagenhaft ansgeschmückt, das historische Ereignis :

Interea ... in familia longe gravissimum valnus accepit, quod pari prodentia ac severitate texit et altus

1) Eine Spur dieses Namens zeigt sich noch in dem Monolog des Fürsten 114, •, wo 'Constantin' über gestrichenem 'Garsias' steht. 
est. Joannem cardinalem et Garsiam tilios secum duxerat; quorum ille major nata vix XVI annum supergressus fuerat. Inter eos ex puerili aemulatione atrocia odia dia nutrita tandem in exitium ntrique verterant. Inter venandum, com seorsim a sociis per devia alter in alterum incurisset, et se invicem pulsasset, Garsias Joannem occupat, et, ut erat truculents et ad omne facinus parata natura, acinace cominus transverberat, statimque ad suos nihil fere tarbato vulta redit. Venatione peracta, cum Joannes non compareret, jam inclinata die, domestici ad eam vestigandum per silvam discurrunt; et equum sessore vacoum nacti, per ejus vestigia ad cadaver deducantur, quod inter repreta jacebat. Inde re ad Cosmum, qui Grosseti erat, per fidos perlata, ille suspicatus quod erat, quanvis ingenti dolore discruciaretur, dissimulato eo rem tegi imperat, et cadaver multa nocte in nrbem inferri et in conclavi aedibns sais proximo collocari; evalgato filium acuta febre, quam dolores vehementes comitati sint, inter renandum correptum, vix loco, in quo eum morbus repentinus oppressaret, exportari potuisse. Tum semotis arbitris ad conclave venit, et sevocatum Garsiam ac de fratre interrogatom, cum vultus contumaci andacis ille factum pernegaret, ad cadaver accedere jubet; eoque renudato, et cruore ad percussoris conspectum mox eballiente, En, inquit, sanguis fratris tui, qui ultionem a Deo atque etiam a me deposcit. Me miserum, qui taleis filios genuerim, aut is superstes fuerim; quorum unum immani parricidio necatum hisce oculis aspicere cogor; alterum, ni impius et iniquus juris inter meos dispensator sim $\theta$ medio tollere, ipse pietate suggerente, compellor! Scelus est patri filinm interficere; sed majus scelus admittam, si enm vivere diutius patiar, qui per fratris perniciem ad patris necem et familiam totam caede ac ferro evertendam gradum fecit. Tum fatente crimen Garsia, et rixao principiom dedisse Joannem affirmante, ita ut nisi peste fratris salutem propriam expedire non licuerit, Cosmus, qui mite Joannis ingenium nosset, pugionem, quo ille 
fratrem confoderat, et adhuc cinctus eo venerat, supplici eripit, nudumque stringens, Hodie pestem domesticam, ne latius exemplo serpat, e visceribus meis avellere decrevi; et, quanquam dulcissimi filii caedem non nisi alterius filii moribus disparis caede expiare possim, malo me posteritas infelicem ac durum patrem praedicet quam imprudentiae et iniquitatis arguat. Tu vero gaude, quod vitam, qua indignns es, cum amittere debeas, in patris manibus, a quo cum accepisti, depositurus sis. Quo dicto Deum comprecatus, ut factum comprobaret, et sonti filio gratiam delicti faceret, enm eodem pugione, quo fratrem confecerat, juxta Joannis cadaver interfecit. Calamitatem hanc paucis ac fidis tantum cognitam, ne sibi ac universae familiae nuper in imperio fundatae noceret, silentio praeteriri voluit prudentissimus parens ac princeps, morte filiorum tunc suppressa, et mox fama sparsa, ex populari morbo alterum post alterum extinctos: famam eam adjuvit coeli intemperies, qua plerique ea aestate ex contagiosis morbis periere. Exequiae deinde utrique Florentiae magna pompa celebratae : et Garsias inprimis oratione publica laudatus, quo magis res tegeretur. Nec multo post Helionora Toletana tot liberorum parens, sive ex naturali stomachi infirmitate, qua jam a longo tempore laborabat, sive moerore ob domesticam jacturam contracto fatis concessit: et ita Cosmi domus, tribus funeribus intra paucos dies afflicta ...

Dieser Stoff ${ }^{1}$ ) konnte einem Dramatiker schon interessant sein, besonders in jener Zeit. 'Un fratello che uccide il fratello, e un padre che vendica l'ucciso figlio coll' ucciderne un altro; certo, se mai catastrofe vi fu e feroce e terribile, e mista pure ad un tempo di somma pietà, ella era tale ben questa ${ }^{3}$, so ruft Vittorio Alfieri in seinem Parere über seine Tragödie Don Garzia aus

1) In Meinhards Nachlass befand sich gleichfalls cler Plan zu einer Tragödie über denselben Stoff. 
(Tragedie. Parigi Anno XI. [1803] tomo sesto p. 160). Sie behandelt denselben Stoff.

Kutschera hat zuerst darauf hingewiesen (S. 79), dass neben dieser geschichtlichen Sage wohl noch ein anderes Faktam anf Leisewitz von Einfluss gewesen sei, nämlich die Verschwörung der Pazzi gegen die Mediceer. Zufällig hat auch Alfieri 'La Congiura de' Pazzi' in einer Tragödie behandelt. Hier fand Leisewitz mehrere Charakterzüge, die Namen : Julian und Bianca, und die Liebe zweier Rivalen zu demselben Mädchen, Camilla Cafarelli. ${ }^{1}$ ) Aber charakteristisch ist die Ablösung des menschlichen Konfliktes von allem, was es für den ganzen Staat wichtig machte; ganz wie Lessing seine Emilia Galotti aus der römischen Geschichte heransschälte. Nur nebenbei wird bei Leisewitz der Folgen gedacht, welche die Geschehnisse für Tarent haben müssten, das allgemein Menschliche steht ganz ausschliesslich im Vordergrunde. Darin haben wir jedesfalls Einfluss Lessings za erkennen, den wir noch in vielen Momenten des Trauerspieles heraushören. Otto Brahm hat, Katscheras Darstellung S. $89 \mathrm{ff}$. erweiternd, sehr einsichtig darüber gehandelt in seinem Aufsatze ' $\mathrm{Zu}$ Julius von 'larent' (Archiv für Litteraturgeschichte 10, 209-217). Es sei darauf verwiesen, weil ich auf eine ästhetische Würdigung nicht eingehen kann.

Leisewitz war also mannigfach zur Produktion angeregt and brachte sie, wie wir sahen, in Göttingen fast fertig; er zögerte mit dem Abschlusse, welchen erst die Hamburger Ankündigung veranlasste. Jedesfalls hat er noch im Juli 1775 an dem Werke geändert, denn sein Frennd Thaer schlog ihm eine Anslassung in $V 1$ der alten Fassung vor; darnach erst kann Leisewitz die jetzige

1) Bei Klinger heisst die von Guelfo angebetete Braut Ferdinandos: Camilla, demuach scheint auch er die Geschichte der Pazzi mit benutzt zu haben. Die Kenntnis dieses Stofies haben wohl Macchiavellis Florentinische Geschichten vermittelt, wo die Verschwörung der Pazzi im 8. Buch erzählt ist. 
Fassung von V 1 gewählt haben. Den Brief Thaers hat Kutschera als 1. Beilage seiner Monographie drucken lassen; er enthält ein begeistertes Lob des Stückes, denn für ein Urteil sind Thaers Sinue zu hoch gestimmt. Das Matteste gefällt ihm so gut, als das, was ihm in anderen Trauerspielen stark vorkam. 'Nur einige von Deinen Scenen gegen andere von den Deinigen gestellt, sind schwächer. Die sechste Scene des ersten Acts ist zu erzählend; auch die folgende wäre kalt, wenn nicht einige Stellen voll von Empfindung seines alten Vaters ihr Feuer gäben. Ueberbaupt ist die Rolle der Cäcilia, gegen Deine andern Personen, zu matt; sie könnte wegbleiben. - Nein, dann fiele die sechste Scene des zweiten Acts und verschiedene Gedanken des darauf folgenden Monologs weg. Es scheint als ob Cäcilia wirklich den Julius liebt, und nur aus freundschaftlicher Grossmuth die Liebe unterdrückt; aber es ist nicht deutlich genug und der Zuschauer merkt es kaum. Darf ich's wagen, Dir eine Besserung vorzuschlagen? - Du könntest, deucht mich, die Rolle der Cäcilia verschönern, weun $\mathrm{Du}$ das etwas merklicher machtest. Man sieht fast bei allen Personen widerstrebende Affecte so schön mit einander streiten, wenn $\mathrm{Du}$ auch bier Freundschaft und Grossmuth bei einem Weibe mit der Liebe kämpfen und jene überwinden liessest. Dadurch könnte dann auch dem, was Cäcilia in dem Auftritt mit der liebenswürdig rasenden Blanka sagt, mehr Feuer gegeben werden. - ...

'Die Drohungen des Julius gegen die Aebtissin schicken sich nicht $z \mathfrak{u}$ seinem Charakter, weit schöner die Art, wodurch er sie nachher gewinnt. Aber ich bedenke nicht, dass die Liebe den Sanftmüthigen zur Wuth bewegen, den Wütherich zum Lamme machen und überhaupt alle (haraktere auf einige Zeit verwandeln kann.

'Aus der Scene der beiden Soldaten liess' ich das: 'Nachher gieng' — - 'herum' weg. Mich deucht, das gehört so nicht in den Ton, womit Soldaten eine Gespensterhistorie erzählen ...? 
Man sieht, dass Leisewitz diesen Brief nicht vergebens empfing. Leider kennen wir Herders Schreiben nicht, vielleicht hat auch dieses Anlass zu Änderungen gegeben.

Endlich war die Schlussredaktion erfolgt und das Stück konnte nach Hamburg abgehen. Sein Schicksal ist bekannt. Zufällig waren drei Stücke eingereicht worden, welche den Brudermord behandelten. Im 'Hamburgischen Theater' Bd. 1 1776, lesen wir darüber folgende Nachricht (Henneberger a. a. O. S. 114): 'Sonderbar wars, dass kurze Zeit auf einander drei Trauerspiele eingesandt wurden, die alle drey den Brudermord zum Gegenstand hatten. Das erste: Die unglücklichen Brüder, war zu leer an Handlung, nicht überdacht und reif genug, obschon einige Scenen vortbeilhaft und Erwartung erregend angelegt, die aber unbefriedigt blieb. Das zweite hiess: Julius von Tarent, handlungsvoll, schön dialogirt, voll Verve und Geist; alles entdeckt den Kenner der Leidenschaft, den denkenden Kopf, den Sprecher des Herzens, und kurz - den Dichter von Talenten; es war des Preises entschieden werth, bis ihm das dritte, die Zwillinge, denselben dadurch abgewann, dass es die mächtige, gewaltige Triebfeder der unentschieden gebliebenen Erstgeburt voraus hatte. 'Wer beweist mir, dass nicht ich der Erstgeborene von uns Zwillingen war?' Das entflammt den wilden hintennach gesetzten Guelfo, und darüber fallen sie beyde.'

Das erste Stück 'Die unglücklichen Brüder' soll die erste Bearbeitung der Bergerschen 'Galora von Venedig’ (Leipzig 1778) gewesen sein, wie Sauer (Joach. Wilb. v. Brawe Quellen and Forschungen 30, 118) nachzuweisen suchte. Auch ihm liegt die Geschichte der Söhne Cosmus zu Grunde. Hier muss der merkwürdigste Zufall gespielt haben. Nicht so zufällig war die Wahl desselben Stoffes durch Klinger. Eine findige Kombination Erich Schmidts (Anzeiger für deatsches Altertum und deutsche Litteratur 3, $198 \mathrm{f}$.) lehrte, dass wahr- 
scheinlich Johanu Martin Miller während eines kurzen Aufenthaltes zu Giessen in der letzten Juliwoche 1775 Klinger von Leisewitzens Drama und seiner Preisbewerbnng erzählt und Klinger dadurch zam Wettbewerb angeregt habe. Klinger trug den Preis davon and sein Stäck eröffnete den ersten Band des Hamburgischen Theaters, 1776.

Minor hat in seinen Quellenstudien zur Litteraturgeschichte des 18. Jahrhunderts in Zachers Zeitschrift für dentsche Philologie 10, $55 \mathrm{ff}$. u. a. auch über die Hamburgische Preisausschreibung gehandelt, and neben den Stücken, die eben erwähnt warden, auch noch Schinks Gianetta Montaldi als Konkurrenzstïck aufgeführt. Er hätte sich zur Begründang auf Schinks Epigramm in dem Berliner litterarischen Wochenblatte 1777 1, 48 berufen können, welches lautet:

\section{An Leysewitz.}

Dein $\mathrm{Julius!} \mathrm{er}$ ist ein Meisterstück, Zwar wurde Hamburgs Preis dir nicht Und ihn erhielt nur mein Gedicht Doch gäb ich gern den Preis zurück, Wär ich nur Autor von dem Stück.

Schink.

Ich kann eine Vermutung nicht unterdrücken, welche mich anch verhindert, aus diesem Epigramme die Konsequenzen zu ziehen. Man hat meiner Ansicht nach eine ganz falsche Vorstellnng von der Hamburgischen Ausschreibung; es handelte sich dabei, wie der oben citierte Wortlaut ergiebt, um eine bleibende Einrichtung, um den ersten Versach, eine Tantième für die Dichter einzuführen. Es worden daher 1776 von der Hamburger Direktion, wie wir heute sagen würden, folgende Stücke 'erworben': 1) Klingers Zwillinge, 2) Die reiche Frau von dem jüngeren Lessing, 3) Die Nebenbubler von Engelbrecht, 4) Was sein soll, schickt sich wohl; im darauffolgenden Jahre 1777 Schinks Gianetta Montaldi, welche daher im 2. Bande des Hambarger Theaters ebenso wie die Zwillinge im ersten neben anderen Dramen zaerst veröffent- 
licht wurde, nämlich neben Henriette von Grossmann, Jeanette (Voltaires Nanine) von Gotter, Der besondere Zufall von Bock. Im 3. Bande folgten dann Schröders Hamlet, Gotters Argwöbnischer Ehemann nach Hoadley, Bocks Flatterhafter Ehemann und sein Mädchen im Eichthal; im 4. Bande endlich Schröders Lear und die Schröder-Gottersche Jnliane von Lindorak (vgl. Goedeke 2, 642). Bergers Galora rang also wahrscheinlich mit Schinks Gianetta um den Preis und erschien daher erst 1778 im Buchhandel.

Vielleicht war das dritte im Jahre 1775 eingereichte, mit Leisewitz and Klinger ringende Stück Rathlefs Drama: Die nngleichen Brüder oder der Schiffbruch war sehr glücklich, welches dann in Jena 1779 erschien (Goedeke II $1084 \mathrm{f}$.); ich kenne dieses Schanspiel nicht.

Ich glaube, meine Vermutung hebt alle Schwierigkeiten, welche Minor und Sauer sahen und erklärt das Vorgehen Schröders. ${ }^{1}$ )

Aber das grosse Publikum, die Kritiker und Theaterdirektoren korrigierten das Urteil der Hamburger, als ihnen beide Stücke durch den Druck zur Prüfung vorgelegt wurden. Auch der 'Julius von Tarent' erschien im Jahre 1776, freilich ohne den Namen Leisewitzens, ja ohne seinen Willen (vgl. Henneberger a. a. 0. S. 115). Mit dieser Publikation durch die Weygandsche Buchhandlung in Leipzig war es ihm sonderbar genng gegangen, denn wenn der Dichter wünschen muss, blos seine Worte, und nor so wie er sie niederschrieb, weiter vermittelt $\mathrm{zu}$ sehen, so traf es Leisewitz schlecht genug. Dies ergiebt jetzt erst das Studium des Originalmanuskriptes.

Sorgfältig hatte Leisewitz jede Periode, selbst jedes

1) Ähnlich fasst die Sache jetzt auch Eugen Wolff in seinem Aufsatze 'Das sogenannte Hamburger Preisausschreiben' (Zeitschrift für deutsche Philologie 21, 39-47), auf welchen ich bei der Korrektur noch verweisen kann. 
Wort abgewogen, zahlreiche Korrekturen im Text und an den Rändern seines Manuskriptes beweisen, wie streng er feilte: sorglos aber überliess er die Abschrift seines Werkes für die Hamburger Preisbewerbang und dann für den Druck fremden Händen. Daraus ergab sich eine Reihe von Missverständnissen, welche bereits den ersten Druck verunstalteten; und bei der weiteren Verbreitung erfuhr der Text kein besseres Schicksal. Unser Fall ist so lehrreich für die Textüberlieferung überhaupt, wie kaum ein zweiter, darum müssen wir eingehender bei ihm verweilen.

Dass nicht Leisewitz selbst sein Werk abschrieb und so eine endgiltige Redaktion herstellte, vermutete ich aus der Beschaffenheit der Änderungen, welche mehr Febler als Besserungen schienen. Als ich nun das Originalmanuskript einer genauen Prüfung unterzog, fand sich auch die Bestätigung dieser Ansicht, denn wir können die Thätigkeit des Abschreibers an verschiedenen Stellen des Originalmanuskriptes direlkt beobachten. Er unterstrich nämlich mit einer viel blässeren Tinte, als die Leisewitzische war, jene Wörter und Phrasen, welche er nicht $z u$ lesen imstande war. In seiner Abschrift muss er dafür Lücken gelassen haben, welche nach Rücksprache mit Leisewitz ausgefüllt worden sein dürften. Dabei geschah es aber, dass eine solche Lücke nicht ergänzt wurde und deshalb ein Wort des Originals fortblieb. Dies ist 21, 17 der Fall. Im Texte stand: 'Warum rief mich itz mein Vater aus dem Kriege wider die Ungläubigen', das Wort itz konnte der Abschreiber nicht lesen, wie ihm denn überhaupt die $t z$ der Handschrift im Anfange Schwierigkeiten gemacht baben, unterstrich es daher und liess wahrscheinlich in seiner Kopie eine Lücke; bei der Revision durch Leisewitz warde dies übersehen, was mit ein Beweis ist, dass Leisewitz die Kopie nicht auf Grund einer Kollation verbesserte, und so blieb dieses 'itz' im Texte fort.

Unterstrichen sind noch folgende Stellen, welche im 
ersten Drucke nicht spationiert erscheinen und durch blässere Tinte die Provenienz der Striche verraten: 14,4 'mir antworten', was wirklich sehr undeutlich geschrieben ist; Leisewitz muss es verbessert haben, trotzdem erscheint im Druck ein Fehler, indem 'Bruder' umgestellt wurde. 15, 19 'lass Deinen Aspermonte', Leisewitz hatte 'Deinen' abgekürzt, 'lass' in seiner Weise einem 'loss' ähnlich geschrieben, 'Aspermonte' steht sehr undeutlich geschrieben über der Zeile. $16,5 \mathrm{f}$. 'ueben' war wie 16, 7 'reben' in dem Worte 'Weinreben' geschrieben, der Abschreiber unterstrich beide Wörter, ebenso 'Ahnherrn Theodorichs', es ist in der Handschrift zweifelhaft, ob Leisewitz nicht 'Theoderichs' schrieb. 16, 7 'reben' in 'Weinreben' unterstrichen. 16, 12 'stunde', welchem jedes dialiritische Zeichen fehlt. 16,13 'löre', in der Handschrift schien 'hüre' oder 'füre' zu stehen, was dem Abschreiber unverständlich war. 17, \& 'Fechtschulen' and 'Syllogismen'. 17, a nahm der Abschreiber Anstoss an den beiden sehr unähnlich geschriebenen 'erweisen'. 17, 18 'Zorne', er machte daraus 'Zorn'. 17, 16 f. 'Feld Lager', was auch wirklich sehr undeutlich ist. 18,10 'worin'. 18, 11 und 18, 18 'letzte' und 'zuletzt tritt', Leisewitz schrieb das ' $t z t$ ' wie ' $s t$ ' und 'tritt' wie 'wilt'. $19,18 \mathrm{f}$. ist ein ganzer Satz, welchen Leisewitz sehr flüihtig am Rande nachgetragen hatte, vom Abschreiber unterstrichen, dabei hat er ein 'aber' vergessen, aus dem einzig richtigen, jedoch in der Handschrift gekürzten 'ihnen' ein unverständliches 'ihm' gemacht und das vor der nachgetragenen Stelle im Texte nicht gestrichene '(ab)' ausgelassen. Auch hier sieht man wieder, dass Leisewitz die Abschrift unaufmerksam revidierte. 20,6 'brennensten', wirklich schreibt er dann 'brennende' und lässt 'die' aus. 20,8 'sie immer', weil Leisewitz 'immer' abgekürzt batte. 20,11 'Thorheiten', was wie 'Thieheiten' geschrieben war. 20,13 'unthätigen Knaben', weil besonders 'Knaben' sehr undeutlich ist. 20, 16 'Mar|cus Porcius'. 21, 7 'Alexanders'. 21, 8 'Cicero'. 21, 12 'Le- 
ben' und 'Thaten'. 21, 16 'iede', dem der i-Punkt fehlt, unterstreicht der Abschreiber zuerst, dann aber hat er es richtig gelesen und nun den Strich getilgt. 21, 17 'itz'. 22, 5 'Seyn Sie nicht unwillig'. 22, 10 'Wehrt'. 22,17 f. 'schwatzt' und 'wimmert wo'; das letztere konnte eher 'erinnert' gelesen werden. 23, $18 \mathrm{f}$. 'war es doch nur ein halber'. 24, 6 'streichelt'. 24, 8 'abschälet'. 24, 16 'seye mir'; wirklich schrieb er dafür 'seyn mir', was Leisewitz unverbessert liess. $24,18 \mathrm{f}$. in 'Lorbeer Blattchen mehr' wurde ' - chen mehr' unterstrichen, der Abschreiber machte '-gen mehr' daraus. 24, 19 'versetzte', was wie 'verfehle' aussah. 54, 12 'Behauptung'; doch ist hier die Sache unsicher; der Abschreiber hat sich eingelesen, wir begegnen seinen Strichen nicht weiter.

Nennen wir die endgiltige Niederschrift in dem uns erbaltenen Originalmanuskripte Leisewitzens $A$, so ist von ihr zu unterscheiden die vom Abschreiber hergestellte Kopie $C$, welche Leisewitz revidierte; dabei hat er entweder, wie wir sahen, die Fehler des Abschreibers verbessert oder aus Unachtsamkeit unverbessert gelassen; so lesen wir $84,11 \mathrm{f}$. in $A$ :

'Und dieser Wechsel von Metten und Vespern, von Begierden und Reue das ist es was sie das Leben nennen und Jugend der Frühling des Lebens?

Gott was gibt meiner Seele Friede - vereinigt diese Empfindungen von denen eine die andre bekämpft, und diese Gedanken von denen ieder den andern Lügen straft (Pause) Nichts als der Tod, nach Julius mein Lieblingsgedanke -?'

Das giebt einen vortrefflichen Sinn, wenn man richtig interpungiert. Freilich war es ein Resultat zahlreicher Korrekturen, welche man in meinem Apparate nachlesen möge. Diese Korrekturen verstand der Abschreiber falsch und stellte folgenden Text her:

'Und dieser Wechsel von Metten und Vespern, von Begierden und Reue, das ist es, was sie das Leben nennen, and Jugend, der Frübling des Lebens? 
Gott, was giebt meiner Seele Friede - vereinigt diese Empfindungen, von denen eine die andre bekämpft, und diese Gedanken, von denen jeder den andern Lügen straft. (Pause) gedanke -'

Nichts als der Tod, Noch Julius mein Lieblings-

Diesen Unsinn hat Leisewitz unverbessert gelassen, also scheinbar gebilligt, es entstand aus $C$ durch Leisewitzens Teilnahme die verderbte Revision $R$. Ich hob natürlich nur ein Beispiel für viele heraus ${ }^{1}$ ), das Nähere kann man aus meinem Apparat entnehmen. Interessant ist die Stelle 38,12 . In $A$ sagt Julius zur Abtissin über Blanka: 'Was ist älter die Regel der Natur oder die Regel des Augustinus - In meinem Bette will ich sie sehen und wenn sie eine Heilige geworden wäre und einen Nimbus statt des Brautkranzes hinein brächte' u. s. w. In $O$ lesen wir für die hervorgehobenen Worte: 'in meine Kammer will ich sie führen, und wenn' $u$. s. w. Diese Milderung werden wir nicht dem Abschreiber zutrauen, zumal wenn wir uns der oben citierten Worte Thaers erinnern: 'Die Drohungen des Julius gegen die Aebtissin schicken sich nicht zu seinem Charakter.' Wir dürfen also annehmen, dass Leisewitz diese Stelle vor der Absendung seines Manuskriptes verbesserte, dass hier also $\boldsymbol{R}$ eine beabsichtigte Veränderung des Textes durch Leisewitz enthalte, dies um so wahrscheinlicher, als 121, 18 die eigentlich stärkeren Worte des Fürsten 'verflucht mein hochzeitliches Bette und seine Freuden' und 7,8 in Julius' Traum: 'ich führte sie in meine Kammer, - wie ich schon an das Braut Bette trat ...' unbeanstandet blieben. Also nicht alle Veränderungen in $R$ sind direkte Fehler, jedesfalls aber unterschiedliche.

1) Vgl. z. B. noch $34,12.37,11$ f. 39 , 2. 45 , 20. 66, 10. Fast ganz blieb dem Abschreiber die Interpunktion überlassen, bei ihr zeigen sich dann in den Ausgaben die grössten Schwankungen. 
Diesen, vom Originale nicht unerheblich abweichenden, zum Teile fehlerhaften Text $R$ sandte nun Leisewitz nach Hamburg and er wurde dann auch 'ohne Leisewitz' Willen' für die erste Leipziger Ausgabe von 1776 benutzt. Diese Originalausgabe $O^{1}$ war ein verhältnismässig getreuer Abdruck von $R$. Der grosse, nachhaltige Erfolg bewirkte nun, dass $O^{1}$ jedesfalls bald vergriffen war. In der uns auch sonst bekannten Weise des vorigen Jahrhunderts liess nan die Weygandsche Buchbandlung einen seiten- ja zeilengetreuen Neudruck mit derselben Jahreszahl 1776 herstellen, ohne ihn als zweite Auflage zu bezeichnen: $O^{2}$. Leisewitz hatte an ihm eben so wenig Anteil wie an $O^{1}$. Dieser zweite Abdruck zeichnet sich gegenüber $O^{1}$ durch grosse Flüchtigkeit der Korrektur aus, wodurch zahllose Fehler in den Text eindrangen, 2. B. 6,2 f. schrieb $A$ : 'Wie ich Abends anf mein Zimmer trete schiesst der Mond $\mathrm{nur}$ eben ein paar Stralen hinein und die fallen iust auf Blancas Bildniss.' $C$ führte nur die Interpunktion durch, so dass $R$ mit $A$ stimmt; auch $O^{1}$ bringt, abgesehen von der veränderten Orthographie (z. B. 'schiesst', 'just', 'Blankas Bildnis') den Text von $R$ beziehungsweise $A$. $O^{2}$ dagegen druckt statt 'nur': 'nan', wodurch der Text verderbt ist. Alle andern mir bekannt gewordenen Ausgaben (s. a.) nahmen den zweiten, jedesfalls in grösserer Auflage verbreiteten Abdruck zur Grundlage, meinten aber unzweifelhaft die Originalausgabe $\mathbf{z u}$ verwerten. Mir ist bisher nur ein einziges Exemplar von $O^{1}$ in die Hände gekommen, welches sich im Besitze der kgl. Bibliothek zu Berlin befindet; im Jahre 1877 warden mir die vorhandenen Exemplare der 1776er Ausgabe vorgelegt, wodurch ich erst auf den Doppeldruck aufmerksam wurde, der sich bisher der Beobachtang entzogen hatte. Er stammt aus Meusebachs Besitz und trägt jetzt die Signatur $\mathrm{Yr} 6672$. 
Um die Überlieferung deutlich zu machen, stellt sie folgender Stammbaum schematisch dar:

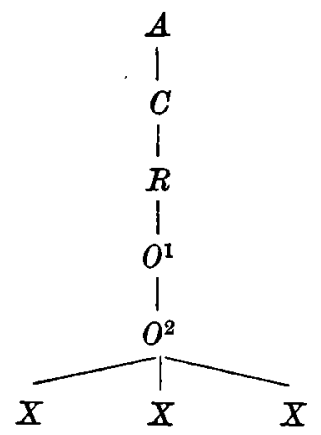

Hätten wir $\boldsymbol{A}$ nicht, dann würde die Textkonstruktion ans blos anf $O^{2}$ führen, schwerlich anf $O^{1}$, also auf eine Form, welche vom Originale ziemlich stark abweicht. Schon $O^{1}$ aber unterscheidet sich nicht unerheblich von $A$, da bereits zwei Veränderungsstufen $C$ und $R$ dazwischen liegen. Dieser Umstand hat methodische Wichtigkeit, weshalb auch in meinem Apparate die Unterschiede zwischen $O^{1}$ und $O^{2}$ im einzelnsten angegeben wurden.

Aus diesem Grunde glaubte ich auch einen möglichst genanen Abdruck von $\boldsymbol{A}$ geben zu mulssen, damit das Bild der Überlieferung so klar als möglich zu Tage trete. Ganz entgegen den Prinzipien dieser Sammlung und den Ansichten des Herausgebers bildet den Text meiner Ausgabe ein roher Handschriftenabdruck, was ich auf Seufferts Wunsch ausdräcklich konstatiere. Meiner Absicht nach soll das vorliegende Heft die Grundlage für Seminarübungen und dgl. bilden, um daran augenfällig zu zeigen, welchen Gefahren das Dichterwort ausgesetzt ist und wie vorsichtig man bei kritischen Bearbeitungen sein müsse. Die Überlieferung ist ein stetes Wachsen von Fehlern and Irrtümern.

Litteraturdenkmale des 18. п. 19. Jahrh. 32. 
Trotz diesen Verderbnissen des Textes zeigte Leisewitzens Julius von Tarent so viele Schönheiten, dass ihm allgemeiner Beifall zu Teil wurde. Lessing hielt das Drama für ein Werk Goethes, alle kritischen Stimmen vereinigten sich in Anerkennung und Lob. Die Zwillinge Klingers wurden 1777 in Wien von Kaiser Joseph verboten, der Julius von Tarent dagegen 1785 gestattet, während freilich der Zensurdirektor Buxbaum (wohl in Salzburg) beiden Dramen dasselbe Schicksal bereitete, aber mit einem bezeichnenden Unterschiede: den Julius verbot er mit den Worten 'Darf nicht produzirt werden', unzweifelhaft weil Nonnen und Geistliche darin auftraten, die Zwillinge dagegen mit der entsetzten Phrase: 'Dieses widernatürliche Stück wird nicht zugelassen' (vgl. Zeitschrift für deutsches Alterthum und deutsche Litteratur 22, 86 und mein Buch 'Aus dem Josephinischen Wien' 1888. S. 81. 83. 86. 149. 150).

Leisewitz gehörte von da $a b$ za den angesehensten Schriftstellern der jüngeren Generation und es wundert uns nicht, dass sich jetzt erst Lessing näher mit ihm bekannt machte. Leisewitz hatte sich nämlich gegen Ende November $1775 \mathrm{zu}$ einem Besuche seiner Schwester nach Braunschweig begeben, wo er sich mit kurzen Unterbrechungen bis zum Sommer 1776 aufhielt. Er studierte Geschichte, um sich für ein alkademisches Lehramt vorzubereiten; es entstanden mehrere Kleinigkeiten, zum Teile Fragmente weitausgreifender Plane, ein Konradin, ein Alexander Hephästion, dazu einiges andere, was ihm seine Freunde nicht ohne Mühe zum Druck abrangen.

Im Juni war Leisewitz in Hannover, schon in den Vorbereitungen zu einer Reise nach Berlin, welche er gemeinsam mit Freund Thaer unternehmen wollte. Sie glaubten, durch ihre schriftstellerischen Arbeiten noch nicht genug empfohlen zu sein und wandten sich nach allen Seiten um Empfehlungsbriefe. Lessing schreibt (Hempel 20, 1, 639) an Ramler aus Braunschweig, den 16. Juni 1776: "Thr Milchbruder (Ebert) hat es zwar 
schon auf sich genommen, den Ueberbringer Dieses, Herrn Leisewitz, bei Ihnen a ufzuführen, wie man in Wien zu reden pflegt. Ich kann es aber doch nicht unterlassen, ihn gleichfalls mit ein par Worten zu begleiten ...' und ebenso warm wie bei Ramler empfahl er ihn bei Nicolai, bei seinem Bruder Karl, Engel, Moses Mendelssohn in Briefen vom gleichen Tage. Zufällig hat sich auch der Brief J. A. Eberts an Ramler erhalten, auf welchen Lessing anspielt; ich danke seine Kenntnis der zuvorkommenden Güte des Herrn Dr. C. Schüddekopf in London. Ebert schreibt aus Braunschweig, den 21. Juni 1776: 'Herr Leisewitz, der Ihnen diesen Brief überbringen, und sich dadurch einen Weg zu Ihrer Bekanntschaft bahnen wollte, wird ihm wohl schon zuvorgekommen seyn; und er braucht auch nicht einen solchen Umweg zu Ihnen zu nehmen; Talent und gater Character können überall gerade zu gehen, wenigstens zu solchen, die beides selbst in einem hohen Grade besitzen. Unterdessen kann doch nicht jeder, wie Lavater, dergleichen Vorzüge einem Menschen an der Nase oder gar am Hinterkopfe ansehen: und daher wünsche ich, mit einer Nachricht nicht zu spät zu kommen, mit der ich eigentlich nicht zu früh hätte kommen können, da sie nothwendig ihm sehr vortheilhaft, und Ihnen sehr angenehm seyn muss. Weil ich ihm wegen einer Verhinderung keinen Brief mitgeben konnte, so eile ich nun Ihnen so bald als möglich zu sagen, dass er der Verfasser eines Werks sey, welches vermuthlich schon Ihnen, und allen Ihren Weiberchen, denen Sie es vorgelesen, - - welches also, sage ich, Ihnen und jenen vielleicht schon Thränen abgelockt hat, wenn ich nach dem Eindrucke, den es bey mir und meiner lieben Louise gemacht, urtheilen darf; eines Trauerspiels, welches mir unser Lessing selbst zuerst mit Freuden bekannt machte, welches von ilsm so aufrichtig bewundert wird, als wenn er nie eine Emilia Galotti gemacht hätte; ob man gleich auch wohl behaupten könnte, dass er, ohne es zu wissen, sich selbst 
in einem Dichter gefalle, der ihn unstreitig nebst der Natur und Shakespeare sich zum Muster gewählt hat; so, wie ohngefähr Raphael sich selbst in seinem Schüler und Nachahmer Julio Romano bewundern mochte. Mit Einem Worte, Hr. Leisewitz ist Verfasser des Julius von Tarent. Seine beiden Dialogen, die Pfändung, und der Besuch um Mitternacht, im götting. Musenalm. 1775. versprachen schon von viel: Aber welch ein Riesenschritt, oder vielmehr welch ein erstaunlicher Sprung ist der von Einer Scene zu einem ganzen Stücke! Und was lässt uns der nicht noch hoffen! Sollte er nicht, wenn er auch nur so fortführe, Göthen einmal in mehr als Einer Betrachtung weit hinter sich zurücklassen? - - -

Auch bei Nicolai liess sich Leisewitz nicht blos durch Lessing einführen. Eschenburg schreibt Braunschweig den 17. Juni 1776: 'Mein theuerster Herr Nicolai, Sie erhalten diesen Brief aus den Händen des Herrn Leisewitz, Verfassers des Julius von Tarent des besten Trauerspiels, das, meiner Meynung nach, seit der Emilia Galotti in Deutschland erschienen ist ${ }^{3} .{ }^{1}$ ) Und Boie schreibt aus Hannover den 24. Juni 1776 gleichfalls an Nicolai: 'Die Bekanntschaft des jungen Mannes, aus dessen Händen Sie diesen Brief erhalten, wird Sie gewiss freuen. Es ist Herr Leisewiz. Sie werden sich mit mir über die schönen Aussichten gefreut haben, die sein Julius von Tarent gibt.'

So empfohlen kam Leisewitz am 25. Juni 1776 in

1) Eschenburg fährt fort: 'Sehr gern hätte ich ihm mehr, als einen blossen Brief mitgegeben; denn Sie erwarten gewiss die noch rückständigen Recensionen von mir ... und bittet Nicolai: 'Vermuthlich ist in Berlin noch die poetische Übersetzung des Shakesp. Julius Cäsar aufzutreiben, die daselbst im J. 1741 gedruckt ist, und einen $\mathrm{Hrm}$. v. B o rk zum Verfasser hat. Sie verbinden mich sehr, wenn Sie sich darnach erkundigen und ein Exemplar für meine Rechnung Hrn. Leisewitz mitgeben wollen .... 
Berlin an, ${ }^{1}$ ) wo kurz vorher, am 19. Juni, sein 'Julius' zum ersten Mal aufgeführt worden war (Plïmicke S. 418); einer Wiederholung konnte er beiwohnen. Wie freundlich er und Thaer aufgenommen wurden, entnehmen wir der Selbstbiographie des Letzteren. Nicolai nennt am 12. Oktober 1776 Gebler gegenüber (Aus dem Josephinischen Wien S. 83) Leisewitz 'einen Mann von vielem Verstande und Scharfsinn', das merke man auch im Stücke, aber auf dem Theater thäte es keine Wirkung. Er fügt hinzu: 'Hr. L. scheint auch eben zum Theater keine Neigung $\mathrm{zu}$ haben, er hat sich hauptsächlich anf die Geschichte gelegt und arbeitet hauptsächlich an einer Geschichte des Westphälischen Friedens. Er ist diesen Sommer beynahe 2 Monate in Berlin gewesen, (wo er auch sein Stück aufführen sahe) und ich habe in seiner Gesellschaft sehr angenehme Stunden gehabt. Er ist ein trefflicher Kopf.'

Die Anknüpfung mit Berlin versprach nicht ohne wichtigen Einfluss zu bleiben. Nach der Rückkehr von seiner Reise nahm Leisewitz seinen Wohnsitz in Hannover, wo er einen angenehmen geselligen Kreis fand. Für Weygand übersetzte er eine 'Geschichte der Entdeckung und Eroberung der kanarischen Inseln' aus dem Englischen, jedesfalls des Erwerbes wegen; er denkt an 'Briefe über die Geschichte', die er aber nie schrieb, er verfasst eine Untersuchung 'Über den Ursprung des Wechsels'; man sieht, wie ihn die Reise aufgerüttelt hat.

Ein paar Anekdoten über Leisewitzens Hannoveraner Zeit finden sich in Johann Georg Zimmermanns 'Kleinen Aufsätzen üher verschiedene Gegenstände', welche das Hannoverische Magazin 1779 enthält. So lesen wir im V. 'Nairheit' (Sp. 601 f.) 'ein kindliches Compliment für

1) Dieses Datum ergiebt sich aus Nicolais Vermerk auf Eschenburgs Briefe: ' 177625 Jun 4 Oct bw.' d. h. nach Nicolais Gewohnheit: 25. Juni 1776 erhalten, 4. Oktober beantwortet. 
einen der grössten Originalköpfe Deutschlands, Herrn Leisewitz. Ich möchte wohl Leisewitzen zum Essen bitten, sagte eine junge Dame in Hannover $\mathrm{zu}$ ihrem Manne. Eines ihrer Kinder fragte hierauf: Liebe Mamma, wer ist Herr Leisewitz? Die Dame antwortet lachend: Herr Leisewitz ist ein schöner Geist. So, sagte das Kind, also ist Herr Leisewitz der liebe Gott.' Und im XXVIII. 'Radotage übers Geniewesen' spricht Zimmermann über 'Divination von dem, was ein Jüngling einst seyn werde', darin heisst es zum Schluss: 'Unter Hunderten, die den von uns weggezogenen Leisewitz, auf den Assembleen unserer Mittelgattung, demüthig and mit gesenktem Angesicht $h$ inter der Thür stehen sahen, sagte denn doch hier und da einer dem andern: dort steht Deutschlands künftiger Robertson und Hume.' Zimmermann erwartete demnach schon damals von Leisewitz nicht weitere dichterische, sondern historische Werke. Wie hier ist auch in Leisewitzens vertraulichen Briefen an ein Mädchen von seinem regen geselligen Verkehre die Rede.

Leisewitz hatte nämlich in Hannover jetzt Sophie Seyler, die Tochter des bekannten Abel Seyler, lieben lernen; sie wurde bei dem Hofapotheker Andreae, dem Schwager ihres Vaters, einem Oheim Leisewitzens, erzogen. Am 1. Juni 1777 gestand Leisewitz dem erst funfzehnjährigen Mädchen seine Liebe und tauschte mit Sophie den Schwor der Treue. Am 12. August hielt er bei seinem Onkel um Sophiens Hand an, wurde zwar nicht abgewiesen, aber auf die Zukunft vertröstet, da Sophie noch zu jung sei. Da sich die beiden Verlobten nur sehr selten ohne Zeugen sprechen konnten, nnterbielten sie einen regelmässigen Briefwechsel, aus welchem Schiller in Herrigs Archiv für das Studium der neueren Sprachen und Litteraturen 1862, 31, 353-410 nicht ohne Missverständnisse und Auslassungen Proben mitgeteilt hat. Andreae hatte nicht verfehlt, darauf hinzudeuten, dass Leisewitz jedesfalls 'mit einer guten Bedienung versorgt' 
sein müsse, wenn er in die Verbindung willigen solle. Leisewitzens Streben ging nun darauf, einen festen Posten zu erlangen; er hoffte auf die Bibliothekarstelle in Hannover, and Sophie ergötzte sich an dem Gedanken, wenn er erst Bibliothekar in Hannover wäre, denn von dieser Stelle konnte man sehr gut eine Frau ernähren (Herrigs Archiv 31, 371). Seine Hoffnung wurde vereitelt.

Da eröffneten sich $\mathrm{ihm}$ zu gleicher Zeit nach zwei Seiten erfreuliche Aussichten, über welche zwei bisher ungedruckte Briefe Leisewitzens an Nicolai Aufschluss geben; durch sie erfahren wir eine bisher unbekannte Thatsache. Der erste der beiden Briefe lautet:

\section{'Hannover d. $5^{\text {ten }}$ Nov. 1777.}

Hochgeschätzter Herr und Freund.

Ihren Brief vom 29sten Jul. habe ich am ersten dieses Monates und das eine Paket noch gar nicht erhalten.

Sie würden mir nach so vielen Gefälligkeiten, eine nene erzeigen wodurch Sie mich sehr verbinden würden, wenn Sie mir es ja glauben, dass ich mich über mein Betragen herzlich schäme, dass ich es selbst schändlich finde dass Sie mich nach einer solchen Aufnahme, die nicht nur über alle Praetensionen, sondern über alle Erwartung ging, durch neue Guttigkeiten auffordern müssen um Ihnen für die alten zu danken. Aber wenn Sie sagen, dass ich Sie vergessen hätte so than Sie mir wahrhaftig unrecht. Ungeachtet ihrer Taub- und Stummbeit hatte ich doch wirklich Dankbarkeit. Das Mägdlein war nicht todt, aber sie schlief.

Für Ihr gütiges Geschenk danke ich Ihnen auf das verbindlichste. Ich habe sehr viel merkwürdiges darunter gefunden. ${ }^{1 / 3}$ wenigstens davon hatte ich noch nicht gesehen und über $1 / 6$ besass ich selbst nicht, und auch so gar unter diesen habe ich Dinge gefunden die mir äusserst angenehm waren z. B. eine Ausgabe von der Anhaltischen 
Canzley, die sich unter vier Exemplaren die ich schon hatte nicht mit befindet. ${ }^{1}$ )

Herr Moses ist seit einigen Tagen hier, und ich habe ihn gestern gesprochen. Er sagte mir dass man in Berlin, bey Besetzung der vacanten Professur der Geschichte zu Halle auf mich Rücksicht nähme, fragte mich auch zugleich um meine Gesinnungen hierüber. Ich bin nicht abgeneigt diese Stelle anzunehmen wenn Sie mir unter annehmbaren Bedingungen angetragen würde, da aber HE. M. nicht genug davon unterrichtet war, so nehme ich mir die Freyheit, Sie zu bitten, mir über folgende Puncte etwas Nachricht za verschaffen.

1) Ob man so ernsthaft auf mich denkt dass es der Mühe wehrt ist sich nach den andern Artikeln zo erkundigen?

2) Wie viel trägt die Stelle fixes Gehalt?

3) Kan der, der sie bekleidet die historischen Collegia lesen die er will?

4) Muss er Magister seyn? - die letzte Bedingung würde mir sehr auffallen. Das 'Ihr sollt Euch nicht Meister nennen lassen’ erkläre ich als ein Hallischer Pietist.

Ich habe Ursachen dass ich Sie mit nächster Post (ein Mensch wie ich sollte eigentlich nie von nächster Post sprechen) um einige Antwort bitten muss. Ich habe einige obgleich entfernte Hofnung dass mich die Wolfenbüttelschen Landstände zu ihrem Secretair wählen werden, der Fall kan vielleicht Morgen eintreten und in der Unwissenheit in der ich über die Hallische Stelle bin, sehen Sie, dass ich das Gewisse fürs Ungewisse nehmen müsste. Ueber zwey Posttage könte ich die Sache nicht füglich hinhalten.

1) Nicolais Teilnahme an der Geschichte des 30jährigen Krieges zeigte sich nachmals darin, dass er im Jahre 1808 von der Witwe Leisewitzens die Sammlung von Flugschriften ankaufte und der kgl. Bibliothek in Berlin vermachte. Vgl. Göckingk, Nicolais Leben S. 105. 
Dass ich nun aber unter diesen Umständen an Si e meinen ersten Brief schreibe, würde vielen Leuten sonderbar vorkommen. Ich denke von Ihnen zu gut, als dass ich mich deswegen entschuldigen sollte.

Leisewitz.'

Nach einem Briefe an seine Braut 'Sonnabends d. $8^{\text {ten }}$ November $1777^{\circ}$ erwartete er erst am Donnerstag eine Entscheidung über seine Zukunft. Dieselbe war 'Sonntags den $16^{\text {ten }}$ November $1777^{\text {' }}$ schon erfolgt, denn Leisewitz nennt Sophie scherzhaft: 'Liebe Jungfer Landschafts Secretärin' und schreibt folgende Adresse: 'An Mademoiselle Seyler, ietzt; Jungfer Landschaftssecretarin ehemals; Jungfer Advocatin'. Und so meldet er denn anch Nicolai:

\section{'Hannover d. $27^{\text {ten }}$ November 1777 \\ Mein wehrtester und gütiger Freund.}

Ich bin heute so zerstreut dass ich Ihnen nur wenige Zeilen schreiben kan, und Vieles was ich Illnen zu sagen habe auf den langen Brief verschiebe den Sie in Kurzem erhalten und nicht stans pede in uno lesen sollen.

Die Wolffenbüttelsche Landschaft hat mich in voriger Woche zu ihrem Secretair gewählet und mir die Vocation darüber schon zugeschickt. Ich brauche mich freylich darüber erst zu Anfang des Januars zu, erklären, allein ich würde Thre Freundschaft nicht verdienen wenn ich Ihnen nicht meinen festen Entschluss bekant machte diese Stelle anzunehmen. Bequemlichkeit und eine grössre Besoldung würden beynahe ieden bewegen diese Stelle der Hallischen vorzuziehen und mich ziehen überdem meine Mutter, Schwester und wackere Freunde nach Braunschweig.

Unterdessen danke ich Ihnen für Ihr Urtheil und Ihre Bemühungen auf das wärmste. Ich mögte so wenig zu den Leuten gehören die der Ausgang dankbar macht als zu denen die er Klug macht. Rechnen Sie auf meine Freundschaft. Diese Versicherung ist von seiten meines 
Herzens kein leeres Compliment, ob es mir gleich leid thut, dass sie von seiten ihrer Thätigkeit bisher nichts bessres gewesen ist. Ich liebe Sie.

Leisewitz.'

Gerade während der Entscheidungszeit hatte Leisewitz eine Unterredung mit Sophiens Tante, welche ihn bat, seltener zu kommen; er ist darüber beleidigt und will gar nicht mehr kommen, bis ihre Verlobung offentlich erklärt ist. Sophie äussert ihre Sehnsucht nach ihm, sucht ihn aber nicht zum Nachgeben zu bewegen. Darther ist Leisewitz sehr erfreut und schreibt ihr am 16. November 1777: 'Es gereicht Dir sehr zur Ehre dass $\mathrm{Du}$ mich nicht batest widerzukommen da Du glaubtest dass ich beleidigt sey. Glaube dass ich es zu schätzen weiss dass Du Dein Vergnügen so grossmuthig meiner Ehre aufopfertest, zumal da Ihr Weiber das so gerne für ein Hirngespinst haltet, was doch so sehr ein wirkliches Wesen ist! Hundert Mädchens von der gewöhnlichen Gattung die mich ${ }^{1}$ ) nicht halb so sehr geliebt hätten als $\mathrm{Du}$ würden mich in Deiner Stelle, gebeten haben die Sache so genau nicht zu nehmen; mich in die Zeit $\mathrm{zu}$ schicken und so oft zu kommen als man es mir erlauben würde.' Übrigens war die Sache beigelegt, die Tante hatte selbst gebeten, er solle wiederkommen. Ich citiere diese bisher ungedruckte Stelle nur, weil wir dieselbe Gesinnung heraushören, wie aus den Worten Guidos 69, 4: 'meine Ehre ist nichts, wenn sie in Betracht des Einen etwas anders ist als in Betracht des Zweyten -'.

Überhaupt zeigen diese Briefe manche Parallele za seinem Drama. So wenn sich Leisewitz im Lobe seiner Braut unterbricht: 'Doch ich vergesse, dass unter Deine Vorzüge auch die Bescheidenheit gehört'; wer denkt dabei nicht an die Scene zwischen dem Fürsten und Caecilia, vgl. 32 , 5. 36,16 ; so wenn er schreibt: 'Verzeihe mir; zuweilen deucht mir meine Liebe so stark,

1) Leisewitz streicht darnach ein unhöfliches 'vielleicht'. 
dass es mir scheint, sie müsste die einzige in ihrer Art sein'; wer denkt dabei nicht an die Worte, welche Aspermonte zu Julius sagt $8,{ }_{17} \mathrm{f}$.: 'Sie sind mir überlegen Prinz - so stark war nie eine Liebe'. Wieder ein anderes Mal schreibt Leisewitz: 'Die Sonntagsmorgen sind mir überhaupt so angenehm, das ist der Geburtstag unserer Liebe. Ich erinnere mich so oft des Ganges aus dem Bosquet, vor dem Hause vorbei, den Garten links hinauf in die Orangerie; an das Zittern; an den Kuss! Das waren Zeiten! - Doch sie werden wiederkommen.' Selbst dies ist ein Nachklang aus dern Drama; Aspermonte fragt Julius 93, 18: 'Das Citronenwäldchen, indem sie Blancan zum ersten mahl sahen und in dem sie so oft träumten, haben Sie vermuthlich (beim Abschied) vergessen?? Julius erwidert: 'Wie solte ich Aspermonte wie solte ich das? ich habe darin noch einige unschätzbare Minuten zugebracht und wenn ich etwas von der Gegend mit nehmen könte so sollte es dies Wäldchen seyn'; und da Julius Blancan 43,17 an ihre Zusammenkünfte im Citronen -Walde mahnt, ruft er ihr zu: 'und ich schwöre Dir diese Tage sollen wider kommen -'. In einem ungedruckten Briefe vom 25. März 1778 schildert Leisewitz der Braut seine Gefühle an einem Posttage: 'Ich stehe schon so heiter auf, bin bis Mittag so zerstreuet dass ich mit aller Mühe meine Aufmerksamkeit auf die nöthigen Arbeiten zusammenhalten muss. Ich finde Dich alsdann aller Orten, in allen Landschaftlichen Acten steht von Sophien, alle Bücher handeln von ihr, ihr Bild tanzt anf allen Seiten ...' Dies ist nur eine weitere Ausführung der Worte, welche Blanca 84, 9 spricht: 'Ich kan nicht weiter [lesen], meine Andacht ist Sünde. Julius! immer um den dritten Gedanken Dein Bild!?

Die Personen seines Trauerspiels sprechen also eine Sprache, welche jedesfalls aus seinem Innersten geflossen ist, $\mathrm{da}$ er sich in den Briefen an seine Braut derselben bedient, ohne dass er sich zu poetischem Ausdrucke künstlich hinaufschraubte. 
Ende Januar 1778 siedelte Leisewitz als landschaftlicher Sekretär nach Braunschweig über. Wir kennen aus den köstlichen Genrebildern, welche Leisewitz in den Briefen an Sophie entwirft, die Personen seiner näheren Bekanntschaft. Am liebsten war ihm die Familie des Professors Schmid, dessen älteste Tochter Charlotte wärmer für Leisewitz gefühlt haben muss; er glaubt sich deshalb verpflichtet, ihr allein in Braunschweig seine Verlobung mit Sophie zu vertrauen, er wollte sie nicht täuschen und konnte nun im Hause Schmids ungezwungen verkehren. Überhaupt nahm er an allen geselligen Freuden Teil, machte mit, was Braunschweig an Zerstreuungen darbot. Litterarisch ruft er während dieser Zeit den Eindruck eines Feinschmeckers hervor, er kostet herum, jetzt einen französischen, dann einen lateinischen Autor, jetzt die geliebten Engländer, dann einen modernen Roman. Während er sich frisieren lässt, blättert er im Seneca und liest den Brief über den Selbstmord. Kann man sich ein köstlicheres Bild jener Zeit denken: ein Dichter, welcher sich frisieren lässt und sich dabei in die Tiefen der stoischen Philosophie versenkt.

Aach schriftstellerisch ist diese Epoche seines I tebens nur reich an Planen, ein Herumschmecken nach allen Seiten; blos seine 'Geschichte des dreissigjährigen Krieges' and sein Lustspiel 'Der Sylvesterabend' sind die festen Punkte seiner schwankenden litterarischen Neigungen, aber auch an ihnen arbeitet er ohne Stätigkeit und innere Nötigung. Es ist mehr ein dilettantisches Spielen, als ein echt künstlerisches oder streng gelehrtes Schaffen. Leisewitz benimmt sich wie ein reicher, wohlsituierter Mann mit schönwissenschaftlichen und wissenschaftlichen Passionen. Dabei aber ist seine pekuniäre Lage nichts weniger als gesichert. Schulden beengen ihn und seine Einkünfte sind so gering, dass er an die Gründung eines eigenen Haushalts nicht denken kann. Zwar eröffinen sich ihm wieder Aussichten, aber sie sind zu wenig klar, als dass er zu hoffen wagte. Am 21. August 1779 
schreibt er an seine Braut: 'Ich schicke Dir hiebey einen Brief von Iffland weil mehr als ein Umstand darin ist, den Du wissen sollst und weil ich durchaus vor Dir keine Geheimnisse haben mag. Du wirst daraus sehen dass man doch in Hannover darauf denkt mich wieder in dortige Dienste zu ziehen. Ich brauche Dir wohl nicht zu sagen, dass ich diesen Vorschlag - mit Deiner Erlaubniss - abschlagen werde. Unterdessen muss die Sache im engsten Vertrauen unter uns bleiben weil mir doch auf allen Fall daran gelegen ist die Hannövrischen Minister nicht vor den Kopf zu stossen. Der Onkel, aber auch er allein, kan die Sache wissen - ich überlasse also alles Deiner weltkundigen Klugheit. Auch Dir wird die Sache angenehm sein. Es ist doch immer ein neuer Stral von Hofnung für unsre Verbindung, ich sehe dass ich hier nicht durchaus gebunden bin, und ich will auch von niemandes Gnade sondern bloss von meinem Verdienste abhängen. Ich gehe auf diesem Wege noch immer fort, cure niemanden, und finde dass mir das keinen Schaden thut.'

Ende des Jahres 1779 kommt neue Hoffnung aus Meiningen; der Herzog fand so grosses Gefallen am Julius von Tarent, dass vom Hofe dieses Drama dargestellt werden sollte. Reinwald musste sich mit Leisewitz in Verbindung setzen, und dieser fasst nun die Absicht, 'in Meiningensche Dienste zu kommen'. Im Januar 1780 wurde seine Tragödie wirklich in Meiningen aufgeführt, der Herzog gab den Julius, er liess sich sogar in dieser Rolle malen (an die Braut 7. August 1780), Prinz George war der Erzbischof, Prinzessin Wilhelmine die Blanka and Prinzessin Amalia die Nonne. ${ }^{1}$ ) Eine besondere Ausgabe des Werkes wurde dazu veranstaltet. Leisewitz wollte persönlich sein Glück versuchen und reiste, nachdem er allerband widerstreitende Nachrichten über Mei-

1) Vgl. Theater-Journal für Deutschland 1780. 16."Stück. S. $127 \mathrm{f}$., darin auch Leisewitzens Brief an Reinwald. 
ningen eingezogen hatte, am 1. August 1780 über Blankenburg, Sondershausen nach Weimar. Kutschera hat S. 41 ff. Leisewitzens Tagebuch über diese Reise im Auszug mitgeteilt, ergänzend kommen die Briefe des Dichters an Sophie hinza, welche daher zum Teil abgedruckt seien; sie bieten freilich nur abgerissene Nachrichten, da Leisewitz der Braut lieber sein Tagebuch zur Lektüre sandte; Schiller hat sie übergangen, obwohl sie geeignet sind zu zeigen, wie unentschlossen, zaghaft, ja timid Leisewitz bei all seiner gesellschaftlichen Gewandtheit gerade dann war, wenn es sich um etwas Entscheidendes handelt; er.ist überbescheiden, trotzdem er seinen Wert fühlt, er ist ängstlich im Thun trotz seinen energischen Wünschen; aber vor allem, er hat jenen schönen, echt männlichen Stolz, welcher nicht der Gnade, sondern dem eigenen Verdienste Befördernng danken will; er rechnet auf eine Stelle, weil er seine Kräfte kennt, weil er glaubt, nutzen zu können; er drängt sich nicht hervor, er will hervorgezogen sein. Diese stolze Bescheidenheit, dieser Unabhängigkeitssinn treten uns in den Reisebriefen deutlich entgegen and gemahnen uns an seinen Aspermonte.

Der erste ist aus Blankenburg, den 3. Angust 1780; darin heisst es: 'Die Reise hat mich zwar angegriffen aber ich befinde mich doch sebr wohl. Ich bin wie Da siehst ietzt in Blankenburg und wünschte hier immer za bleiben, und wie ich in diese Gegend kam grüsste ich sie sogleich mit dem Gedanken wer hier mit Sophien leben könte! Sie verdient es und ist weit schöner als die Rehburger, ein höchst glückliches Gemisch von Allem was die Natur Schauerndes und Sanftes hat, von Felsen die wie Thürmer nnd oft nur auf einer Spitze auf einander stehen, von fruchtbaren Ebnen, Bergen, Wäldern, verwüsteten Schlössern - Das hiesige Schloss hat die herrlichste Aussicht in viele Länder, auf eine Menge von Städten, und tragt selber sehr vieles zu Verschönerung der Gegend bey. Es liegt auf einem sehr hohen Berge und man hat die Felsen zum Theil mit in die Manern 
gezogen, die Stadt liegt an diesem Berge und gibt einen höchst sonderbaren Anblick indem die Spitzen der Thürmer weit unter dem Fusse des Schlosses liegen, ungeachtet diese auch weit über das Thal erhaben sind und die Einwohner zum Theil auf sehr hohen Treppen zur Kirche gehen. Die Strassen sind oft so steil, dass mir schwindlich wird, and es war mir ein sehr befremdender Auftritt als ich gestern aus einem Garten in das zweyte Stockwerk eines Hauses ging.

'Die Menschen scheinen die Schönheiten dieser Natar zu fühlen, und ein sehr gutes Häufgen ausznmachen. Ich bin von allen mit einer solchen offnen Gefälligkeit anfgenommen dass es mir schwer wird mich von ihnen zu trennen, ungeachtet es erst gestern aus Morgen und Abend der erste Tag ward - Anch einige hiesige Weiber haben iedoch in allen Ehren, meinen völligen Beyfall ...

'Ich habe hier von einem Herrn von Hanstein die Meinigische Gegend sehr rübmen hören welches mir eine sehr angenehme Nachricht war, denn ich habe mir nach verschiednen, was ich darüber gelesen habe, kein sehr vortheilhaftes Bild davon gemacht.

'Ich reisse mich Morgen von Blankenburg los, und gehe nunmehr so geschwind als es meine Gesundheit, die Hitze, und die Harz Wege erlauben nach Weimar.'

Aus 'Nordhausen den $5^{\text {ten }}$ August 1780 ' schreibt er zam zweiten Male: 'Diese Stadt interessirt mich bloss deswegen weil sie Nanetchens Geburtsstadt ist, ihr Vater war ein hiesiger Brannteweins Brenner. Das erste ist freylich zufällig das zweyte aber nothwendig, denn alle Leute sind hier Brandteweinbrenner. Sie wohnt mit Amaranthen in der Nachbarschaft, es ist mir aber wegen der entsetzlichen Harz Wege unmöglich gewesen sie zu besuchen, ob ich gleich mit ihrem Manne [Göckingk] in Briefwechsel stehe."

Am 7. August meldet er ihr nur kurz seine Ankunft in Weimar und fugt hinzu: 'Ich habe Gelegenbeit gehabt hier nähere Nachrichten von Meiningen einzaziehen die 
mir alle sehr schmeicheln. Der Herzog ist ausserordentlich für mich eingenommen und hat sich sogar als Julius mahlen lassen Nous verrons'. Im nächsten Brief aus Weimar den 11. August 1780 lesen wir: 'Wahrscheinlich wäre ich nicht mehr in Weimar wenn ich nicht den Oberhof Prediger Herder der kurz nach meiner Ankunft verreisst ist erwartete, diesen grossen Mann mochte ich gar zu gerne kennen lernen, und wie er mir schreibt so interressirt es auch inn ungemein meine Bekanntschaft zu machen. Wir baben in den beyden Tagen dass wir hier zusammen gewesen sind über unsre Zusammenkunft correspondirt, und sind durch die sonderbarsten Umstände abgehalten worden einander zu sehen. Heute Abend komt er wieder, und ich gehe spatestens am Sonntage nach Erfurt, wo ich keinen ganzen Tag bleiben werde und als denn nach Gotha.

'Göthen habe ich zwar kennen lernen aber auch noch nicht genau gestern Abend haben wir einander wider bey einem Souper bey einem Geheimten Regierungs Rathe von Schardt verfehlt, indem ich nicht hinkommen konte.

'Auch Wielanden habe ich kennen lernen, und bin ein paar Stunden bey ihm gewesen - ich mag ihn aber nicht weiter kennen. Einen so elenden Mann von grossen Talenten habe ich noch nicht gesehen. Man wärde Eurem Geschlechte Unrecht thun wenn man seine Eitelkeit weibisch nennte; sie ist mehr als kindisch. Er hat nur zwey Gegenstande von denen er spricht dass ist er and Wieland.

'Der regierende Hof ist die aller meiste Zeit dass ich hier bin auf dem Lande gewesen, und ich bin da also nicht praesentirt. Der verwittweten Herzogin bin ich auf dem Lustschlosse Ettersburg vorgestellet und gar gnädig behandelt worden.

CAm meisten habe ich mich mit einer artigen Frau amüsirt, die mich alle Tage bitten lasst. Sie ist reich and Wittwe. $\mathrm{Du}$ wirst also als ein vernünftiges Frauenzimmer wohl einsehen, dass aus einer gewissen Heyrath 
von der ich mich vordem wohl ein und anders habe entfallen lassen nichts werden kan.

'Wegen Meiningen habe ich hier eine nicht allzu angenehme Nachricht erfahren. Der Hof wird nächstens nach Gotha kommen, unterdessen habe ich mir fest vorgenommen auch so lange in Gotha zu bleiben, bis ich den Herzog in Meiningen allein treffe - den einzigen Fall ausgenommen das Se. Durchlaucht ewig in Gotha zu bleiben gedachten. Er hat sich in Junius verheyrathet.'

Am 14. August kann er nur sagen, dass er noch in Weimar sei. 'Ich habe mich schon ein paarmahl erbitten lassen noch hier zu bleiben, und gestern sogar die schon bestellten Pferde abbestellen lassen. Ein sehr artiges Mädchen von einer Sängerin, und Göthe haben die meiste Schuld, denn ich wüsste sehr wenig Frauenzimmer die mir so gefallen hätten als diese Sängerin und wenig Gelebrte die mich so interressirten als Göthe.

'Aber heute Abend will ich durchaus in Erfurt seyn und wenn mich auch Gesang und Gelehrsamkeit in höchst eignen Personen abhalten wollten.'

Aus Gotha den 16. August 1780 berichtet er dann: 'Ich habe mich endlich zusammengenommen, Weimar verlassen und bin gestern über Erfurt hier angekommen... Ich weiss nun noch nicht wie lange ich eigentlich hier bleibe, die Umstände wissen es wahrscheinlich besser als ich, einige Tage das ist 8 bis 10 muss mein Aufenthalt wenigstens dauern, wohlstandshalber. - Denn gehe ich nach Meiningen.

'Ich muss Dir gestehen dass mir der Muth immer mehr sinkt ie näher ich dem entscheidenden Orte und der entscheidenden Zeit komme. Zugleich aber bemerke ich doch mit einigen Wohlgefallen eine gewisse Festigkeit, und einen gewissen tröstenden Glauben dass Meiningen nicht die Welt ist. Wenn es dort nicht geht so setze ich vieleicht meine Reise fort um mich zu zerstrenen, denn Zerstreuung würde ich doch immer nöthig haben ... 


\section{$\mathbf{L}$}

'In Erfurt habe ich einen sehr interessanten Auftritt mit einem Carthäuser Mönch gehabt, wovon ich Dir mit nächster Post mehr schreiben will. ${ }^{1}$ )

'Ich bin noch nicht in Gotha gewesen und wohne vor der Stadt in so schönen Zimmern dass ich nie bessre verlange...?

Am 19. August teilt er ihr mit, dass er noch zwölf oder vierzehn Tage werde in Gotha bleiben müssen und am 21. weiht er sie in seine Hoffnungen und Befürchtungen ein, er ist 'nicht ganz ohne alle Aussichten, ob es gleich mit dem Meiningischen Proiecte nichts seyn wird'.

'Es wird ... zu Deiner Zufriedenheit gereichen wenn ich Dir sage dass meine Idee nicht sowohl gescheitert ist als dass ich sie aufgebe. Der Herzog von M. ist um seinen Schwager zu besuchen hier her gekommen, und ich habe ihn bey dieser Gelegenheit kennen lernen. $\mathrm{Er}$ hat mir auf das gnädigste begegnet, aber ich finde nach Ueberlegung aller Umstände, dass ich doch nicht klug handeln würde wenn ich die Sache weiter triebe.

' $E r$ ist ohne Zweifel ein Mann von dem besten Herzen scheint mir aber nicht Festigkeit genug zu haben, und wie ich, so gut als die andern Umstände, von

1) Vgl. Schweiger S. 239; Kutschera S. 47. Es war der Pater Vicarius Joh. Georg Stumpf. Leisewitz erzählt: 'Wie ich den Mann in seinem Kloster vor etwa zwei Jahren kennen lernte, so bemerkte ich an ihm eine brennende Liebe zur Lectüre, welche durch Alles das, was die Klosterbibliothek darbieten konnte, schlecht befriedigt war, ob es gleich schien, dass er was seine kleine Sphäre darbot, ganz erschöpft hätte. Ich fand bei ihm eine Menge von Auszügen, ron Sammlungen von abgeschriebenen Manuscripten, Kenntnisse z. B. vom protestantischen Kirchenrechte, die mich in Verwunderung setzten ... Mit alledem verband der Mann eine grosse Gutherzigkeit. Ich war ihm völlig unbekannt: als ich aber nur mit einiger Aufmerksamkeit von einem alten historischen Manuscripte, das er mir zeigte, redete, so machte er mir sogleich von einer $\mathrm{Ab}$ schrift, die er selbst gemacht hatte, ein Geschenk auf eine Art, die mir in der That unvergesslich sein wird.' 
sicherer Hand weiss, sich der Regierungs Geschäfte nicht mit dem grossten Eifer anzunelımen.

'Doch das mogte alles noch hingehen wenn nur die andern Umstände nicht wären - An den Hofe in M. werden vieleicht mehr Cabalen als irgendwo gespielet, wovon ich nahmentliche Beyspiele weiss. Hiezu komt dass in diesem Lande nicht der älteste Prinz allein, sondern alle Prinzen zugleich succediren, und der itzige Herzog mit seinem Bruder nicht zum besten harmoniren soll - Du kannst leicht einselien, in welche Verlegenheiten diese Umstände einen Bedienteu setzen können, er mag als ehrlicher Mann, oder als ein Schurke handeln wollen. Ueber dem sind die öconomischen Umstände nicht die besten, und ich mogte vieleicht gar einen vergeblichen Versuch $\mathrm{zu}$ einer Sache wagen, die wenu sie auch einschlüge leicht zu meinem Unglücke gereichen könte. Ich werde also auch nicht nach Meiningen reisen, sondern noch einige Zeit hier bleiben.

'Ich habe nemlich meinen Plan dahin geändert dass ich auf alle Weise suchen werde in Gothaische Dienste zu kommen, weil mir Gotha besser wie die meisten Orte und eben so gut als Hannover gefallt. Der Herzog ist einer von den edelsten besten Menschen die ich kenne, ein Mann von vieler Wissenschaft, - und der sehr vieles aus mir macht. Das habe ich nicht allein vermuthet, sondern anch andre Leute haben es bemerkt, und ich glaube es auch aus seinem eignen Munde gehört zu haben, als er es gestern der Prinzessin von Meiningen zuflüsterte - Auch seine Gemahlin und sein ganzes Haus, die hiesige Gegend der äusserst gefällige Ton der Leute, kurz Alles reizt mich ausserordentlich.

'Ich weiss noch nicht ob ich mir während meiner Anwesenheit etwas merken lasse - oder ob ich warte bis ich wieder in Braunschweig bin. Von dort werde ich ihm etwas von meiner Geschichte schicken die ilın sehr interressirt. So wohl Er als der Herzog von Mei- 
ningen haben mir Papiere dazu versprochen. Den von Gotha hatte ich nicht einmahl darum gebeten.'

Am 30. August entschuldigt er sich, dass er den letzten Posttag vorübergehen liess ohne zu schreiben, er hatte sich zu lange am Hofe aufgehalten. 'Ich hatte den Tag eine ganz besondre Veranlassung hinzugehen. Abends vorher war Maskerade, von der ich sehr früh wegging weil ich es unerträglich heiss fand, unterdessen mogte sich ein Gerücht ausgebreitet haben dass ich krank sey, denn die höchsten Herrschaften liessen noch denselben Abend fragen wie ich mich befände, und ich hielt es daher für meine Schuldigkeit sothane Gnade in tiefster Unterthänigkeit gleich den andern Morgen zu verehren.

'Die Meiningischen Herrschaften sind nunmehr zurück, ich habe den Herzog noch verschiedene mahle gesehen, bin aber so wohl durch ihn, als durch alle Menschen, und durch alle Umstände in der Meynung befestiget dass ich den besten Weg eingeschlagen bin.

'Im Gegentheile bin ich fest entschlossen hiesige Dienste zu suchen und werde mich deswegen noch einige Tage vieleicht noch acht hier auf halten. Nur bin ich in einiger Verlegenheit wem ich mich anvertraue, erstlich fiel ich auf einen Minister von Frankenberg, jetzt ziehe ich aber einen CammerHerrn von Thümmel - einen Bruder des Geheimten Raths, der die Wilhelmine geschrieben hat, vor. Ich weiss nur noch nicht ob ich mich ihm mündlich oder schriftlich entdecke, zu dem ersten hätte ich in ein paar Tagen eine gute Gelegenheit, weil ich alsdenn mit ihm auf dem Gute seines Bruders seyn werde. Er scheint mir ein sehr ehrlicher Mann zu seyn und dabey äusserst thätig, er hatte schon eine sehr gute Idee von mir und diese muss gestern noch durch ein Frauenzimmer sehr erhohet seyn auf deren Urtheil er viel gibt und die ungemein grosse Güte für mich hat.

'Sonderbar ist es dass ich einem Manne von meimem 
Proiecte sagen muss dem ich lieber nicht davon sagte, das ist Gotter. Er hat zwar die äusserste Gefälligkeit gegen mich wir sind meistens täglich mehr als einmahl zasammen, und er sorgt für mein Vergnügen mit der grössten Sorgfalt, allein es fehlt uns an einer gewissen Vertranlichkeit, und doch stehen wir auf einem gewissen Fusse, dass er es äusserst übel nehmen könte, wenn ich ihm nichts sagte. Ich wollte schon gestern mit ihm reden, konte ihn aber nicht allein treffen.

'Der Herzog schätzt mich, und ich weiss aus vielen Kennzeichen dass ich die Achtung und Liebe vieler Leute habe unterdessen weisst $\mathrm{Du}$ wie es mir in Hannover ging da mir alle Achtung and Liebe nichts half.

'Auf allen Fall - auch auf den Besten - wird mein Schicksal nicht bey meiner itzigen Anwesenheit entschieden werden, ich wünsche das selbst nicht einmahl, und werde sogleich davon reisen, wenn ich meine Sachen angebracht habe. Ich gehe von hier grade nach Braunschweig.

'Aber bestes Mädchen ich bitte Dich lass den Muth nicht sinken. Bedenke, wenn ich in Gotha ankäme, so wäre es ein Glück auf das ich vor einem Jahre nicht gedacht hätte, und kan ich nicht in einem Jahre mein Glück auf eine andre Weise gemacht haben, auf die jetat kein vernünftiger Mensch denken kan. Du wirst nicht daran zweifeln dass ich Dich zärtlich liebe, dass ich unsre Vereinigung eben so heiss wünsche wie $\mathrm{Du}$ es immer thun kannst, aber ich versichre Dich dass ich gefasst bin ....

Nicht so gefasst scheint Sophie gewesen zu sein, denn Leisewitz tröstet sie aus Gotha den 2. September 1780: 'Meine beste ewig Geliebte Ich kan Dir nicht sagen was mir Dein letzter Brief wehe gethan hat, indem ich mir deutlich vorstellen kan, dass meine Nachrichten wegen Meiningen eine sehr üble Wirkung auf Dich gehabt haben müssen, wenn Dir auch die kalte Vernunft meine Gründe auch noch so richtig darstellte ... 
'Ich werde noch den grössten Theil der künftigen Woche hier bleiben, denn wie Du Dich erinnerst habe ich den CammerHerrn von Thümmel zu dem Manne gewählt durch den ich mein Proiect auszuführen gedenke, die LandParthie auf das Gut des Geheimten Raths ist aber diese Tage durch immer verschoben, und wird erst Morgen vor sich gehen. Unterdessen weisst Du dass ich der Mensch bin der ausharren kan, und will dem Dinge auf eine oder andre Art näher kommen und wenn ich als Braunschweigischer Secretair in Gotha alt werden sollte.

'Gottern habe ich auch noch nichts - und also eigentlich noch niemand - etwas gesagt, weil mir immer die Gelegenheit dazu fehlt, neulich waren wir endlich einmahl auf dem Felde allein, und ich merkte mir auf unsrem Spatziergange schon einen Ort wo ich herausrücken wollte, als uns ein Mensch ganz ausser Othem einholte, und uns den ganzen Nachmittag nicht wieder verliess.

'Du wirst Dich vieleicht wundern wenn ich Dir sage dass ich nur deswegen gern in Gotha seyn mögte, weil mir der Ort, die Gegend, die Menschen und der Ton ungemein gefallen, und weil ich Dir hier mehrere Bequemlichkeit als in Braunschweig verschaffen könte aber das ist Alles äusserst wahr, weil ich Dich auch in Braunschweig, wenn kein Unglück dazwischen komt und die Sachen nur so bleiben wie sie sind, übers Jahr um diese Zeit als meine Frau küssen oder das Leben nicht haben will. Eine Stelle in Thaers Briefe an Dich hat mich auf gewisse Gedanken gebracht die mir nach der reifsten Prüfung sehr richtig scheinen. Ich sehe dabey zum voraus dass wir 600 Thaler zu unsrer Haushaltung gebrauchen, und ich denke dass Du damit einig bist. Iffland hat mir versichert dass er nicht so viel verzehre. Nun habe ich von meiner Bedienung 310 Thaler von meiner Mutter 150 macht 460 - und Thaer hat vollkommmen Recht wenn er glaubt dass ich mit Neben Ar- 
beiten leicht 140 Thaler verdienen würde. Ich habe das bisher zu sehr vernachlässigt, werde es aber in der Folge nicht thun und habe mit einem hiesigen Buchhändler schon in dieser Rücksickt gewisse Verabredungen getroffen. Wenn $\mathrm{Du}$ also nichts dagegen hast so ist im künftigen Junius unsre Hochzeit.

'Dieser Plan ist mir so einleuchtend dass ich selbst die Idee ein Canonicat $z u$ kaufen, womit meine Verwandten schon ziemlich zufrieden waren, die mir Thaer aber widerrieth, habe so ziemlich fahren lassen. Wenn wir aber keine Kinder bekommen sollten so würde ich sie wider hervorsuchen und meine Bedienung aufgeben. Ich wundre mich in der That dass ich nicht schon lange auf diese Berechnung gefallen bin und dass sie mir ein andrer erst angeben musste ...' Zum Schlusse versichert er sie, dass Alles, was sie gelesen habe, 'Ja und Amen' sei. Am 6. September kann er endlich melden: 'Ich habe gestern mein Proiect Gottern entdeckt, werde am Freytage mit einem hiesigen Minister davon sprechen und am Sonnabend ganz gewiss abreisen ... Mein Entwurf hat einen sehr guten Anschein man sieht mich bey Hofe gern, und in der Stadt haben Leute, ohne mein Wissen hin und her gedacht wie ich bier bleiben könte, unterdessen wird auch auf dem besten Fall nicht so gleich eine schickliche Stelle offen, und auf dem schlimmsten Fall habe ich Dir meine Entschliessungen gesagt, diese hangen von Gott, Dir und mir, sonst von lieinem Menschen und keinem Fürsten $a b$ - mit den Entwürfen ist es anders ... Am 9. ist er noch immer in Gotha, 'Morgen oder Übermorgen werde ich mein Proiect einem Minister entdecken. Gotter billigt es sehr.'

Wieder in Braunschweig eingetroffen, schreibt er ihr am 19. September, sie werde schon von ihrem Bruder durch Koster wissen, dass er ein paar Tage in Gorttingen gewesen sei, 'gestern bin ich von dort wider zurück.

'Ich bin in langer Zeit nicht so voller Muth und Hofnung gewesen als jetzt, und bin überzeugt, dass sich 
nnser Schicksal in Kurzen zu unsrer Zufriedenheit wenden muss.

'Ich bin nemlich in Gotha von allen Lenten mit solcher Achtung aufgenommen und habe mir - ich kan Dir so etwas wohl sagen - eine so allgemeine Liebe selbst bey dem Herzoge und der Herzoginn erworben, mein Verlangen dort zu leben so deutlich merken lassen, gefanden, dass so viele Leute anch da schon von selber darauf denken, mir so viel Wege zu Correspondenzen und Verbindungen geöfnet; dass es höchst wahrscheinlich ist, ich werde mein Proiect durchsetzen. Ich hoffe Du wirst es daher billigen dass ich unter diesen Umständen das Meiningische Proiect aufgegeben, und in Gotha die guten Bedingungen die man mir machen konte, nicht durch einen zu dringenden Antrag verdorben habe. Ich würde ohnedem wenig damit ausgerichtet haben, weil nun gerade keine Bedienung die sich für mich schickte offen war.

'Gotha hat mir übrigens so gut gefallen dass ich da zu leben wünschte wenn ich auch nicht den Wunsch hegte mit Dir da zu leben, Gegend und Menschen haben mir ungemein gefallen, und es ist noch überdem dorten gegen unsre Gegenden ganz unglaublich wohlfeil. Ich habe in dem besten Wirthshause in 4 Wochen, ein sehr prächtiges Diner und 1 Bouteille Ungarischen Wein mit eingerechnet etwa 23 Thaler verzehrt ...

'Wenn Dir etwas daran gelegen ist, so kan ich Dir mit Zuverlässigkeit sagen, dass ich einigen Weibern in einem ziemlich hohen Grade gefallen habe - Man schien hin und wider von unsrer Verbindung $z u$ wissen, und in Göttingen ist sie eine ganz bekante Sache ...?

Noch eine Aufklärung über das Meiningische Projekt gibt der Brief aus Braunschweig den 22. September 1780: 'Es schien mir wirklich als wenn ich nicht in der Gesellschaft eines Mannes glücklich sein könte, dessen Character ich freylich ehre, der aber immer von Theater spricht, und mich alle Tage quälen würde Comödien za 
schreiben - nicht einmahl an andre Umstände za denken die jch Dir schon geschrieben habe.

'Ich würde mit vielem Vergnügen nach Gotha gehen, ungeachtet ich weiss was Du gegen den Character des Herzogs mit Grunde einzuwenden hast. Ich hätte aus mehr als einer Ursache dergleichen nicht zu fürchten, würde nie ein eigentlicher Liebling eines Fürsten werden, oder auf den schlimmsten Fall mich nur dazu entschliessen weil es nicht anders seyn könte, und weil ich weiss dass ich bald aus der Mode und also bald in Ruhe hommen würde.

'Ich habe in Gotha schon eine Probe im kleinen gemacht, da mich ein paar neue Papageyen ein paar Tage lang bey der Herzogin ausstachen, allein sie wussten sich nicht zu erhalten, and ich stach à mon tour die beyden Cacadus aus ungeachtet da zwey gegen einen waren. Ueberhaupt wird mich Fürstengunst so wenig als Wasser berauschen ...' Diese Gefahr drohte ihm nun freilich nicht.

Die gate Laune, welche die Reise zur Folge hatte, hielt noch eine Zeitlang in Brannschweig vor; er scherzt wohl, da er der Braut mitteilt, wie weit die Nachricht von ihrer Verlobung schon gedrungen: 'Wir müssen doch bedentende Leute seyn dass es in halb Deutschland schmatzt, wenn wir uns küssen'; aber er fühlt doch schwer die Enttäuschungen; so heisst es einmal: 'Der Schlag geschahe nun eben nicht mit Eisen aber er fiel auf Buttermilch - denn meine Constitution ist von diesem Stoffe so bald etwas ins Spiel komt, das Dir unangenehm seyn könte ...' Wiederholt sehen wir in der Korrespondenz mit der Braut, dass nur die Sorge um ihr Glück ihn za seinen Bemühungen um einen einträglicheren Posten antreibt, er möchte sie aus ihrer unangenehmen Stellung befreien, da sie sich im Hause des Oheims nicht sehr wohl befunden zu haben scheint, ihm selbst muss seine Lage in Braunschweig nicht unangenehm gewesen sein; das Amt liess ihm viel Zeit, die Nach- 
mittage hatte er ganz zu seiner Disposition und, wenn nicht gerade die Landschaft beisammen war, konnten auch die Vormittage zum grossen Teile den Privatneigungen gewidmet werden; in dem 'Schreiben eines Reisenden', welches das Deutsche Museum 1783 2, 557 veröffentlichte (Zeitschrift für deutsches Alterthum und deutsche Literatur 22, 92) heisst es: 'Seine Amtsgeschäfte, er ist Landschaftssekretär, hindern ihn nicht an Fortsetzung jener Arbeiten, und er befindet sich in solchen Umständen, dass er sich, wenn er will, seine Musse zu erhalten im Stande ist.'

Wobl aber sehnte sich Leisewitz immer mehr nach eigenem Haushalte, und die Sylvesterbetrachtung im Briefe vom 26. Dezember 1780 lautet bei aller Ergebung, doch melancholisch; er schreibt: 'Ich glaube doch, dass wir vieles durch die Länge unsers Romans gewonnen haben. Wir hätten uns freylich in der Ehe auch kennen lernen aber nicht auf eine so edelmüthige Art. Jetzt haben wir Thüren und Fenster Kisten und Kasten in unsern Herzen einander freywillig aufgemacht, aber nach der Hochzeit wäre das auf eine Art geschehen, die mit einer gerichtlichen Haussuchung, der man sich unterwerfen muss viel ähnliches hat. Wenn ich auf etwas stolz bin so bin ich es auf unsre Liebe und oft in Gefahr mit dem Pharisaer zu sprechen. Ich danke Dir Gott dass ich nicht bin wie andre Leute, Romanenhelden Hände Küsser, Brautschatziager oder auch wie dieser Bräutigam', von welchem sie ihm geschrieben haben muss ...

'Ich habe schon vor einigen Jahren den Entschluss gefasst eine Geschichte des dreissigiährigen Krieges zu schreiben, auf die ein grosser Theil von Deutschland so begierig ist, dass ich mich wirklich für der gar $\mathrm{zu}$ grossen Erwartung fürchte. Denn ob ich gleich nur Anfangs mit ein paar guten Freunden davon gesprochen hatte, so wurde es sogleich in allen Zeitungen bekannt gemacht.

'Unterdessen ist es höchst wahrscheinlich dass ein 
Buchhandler ein gutes Stück Geld damit verdienen kan and ich bin deswegen mit einem in Gotha, der mir ein guter Mann zu seyn scheint in Unterhandlung getreten, und bin mit ihm über einen Hauptpunct bereits richtig, der darin besteht dass ich einen Theil der Summe zum Voraus bekomme.

'Gewohnlicher Weise werden den Verfassern die Bücher bogenweise bezahlet, ich habe aber die Idee womit mein Mann auch zufrieden ist, das Ganze auf einmahl zu verkaufen, and die Summe in vier Terminen zu erhalten. Ich rechne etwa auf 800 Thaler und iahrl. auf 200 wodurch ich also mein Einkommen wirklich verbessern würde."

Er rechnet wie eine bekannte Lustspielfigur immer wieder, ob sein Einkommen nicht doch ausreiche, seine Sophie zn erhalten und ängstlich schwankt er zwischen $\mathrm{Ja}$ und Nein. Im Februar 1781 meldet er der Braut, zum ersten Mal am 13.: 'Lessing hat verschiedene Anfälle von Stickfluss gehabt und ist noch immer in Gefahr ... schon drei Tage darauf hauchte Lessing aber seine Seele aus; damit war das Wolfenbüttler Bibliothekariat erledigt, auf das auch Leisewitz im Geheimen hoffte, doch scheint er keine Schritte deshalb unternommen zu haben. Bekanntlich wurde Langer Lessings Nachfolger. Da beschliessen denn die Liebenden gemeinsam die vielleicht später doch eintretende Schicksalswendung abzuwarten, und am 13. September 1781 wird Sophie Leisewitzens Frau; das Glück, welches sie sich versprochen hatten, ging in ibrer Ehe voll in Erfüllung, nur der Kindersegen blieb aus, welchen sich Leisewitz am 30. März 1779 in seinem scherzhaften Zukunftsbrief ausgemalt hatte (Herrigs Archiv 31, 372 f.); das Ehepaar nahm 1787 Gretchen Cordemann an Kindesstatt an.

Leisewitz war glücklich mit seiner Sophie, wenn es auch im Anfang etwas knapp zugieng und die Frau genötigt war, dem Pfandhaus ihr persönliches Interesse zu widmen. Es war eingetroffen, was Leisewitz - auch 
hier Schillers Vorgänger - seiner Blanca in den Mund gelegt hatte 47, 4: 'diese Hütte ist klein - Raum genug $\mathbf{z u}$ einer Umarmung - das Feldgen ist enge Ranm genug für Kuchenkräuter und zwey Gräber und dann Julius die Ewigkeit - Raum genug für die Liebe.' Es kamen auch für sie bessere Zeiten, denn Leisewitz machte sich immer mehr geltend; ohne dass er sie gesucht hätte, kamen Anerkennung, Wirksamkeit und Auszeichnung. 1786 wurde ihm die Erziehung des Erbprinzen Karl Georg August übertragen, und er wusste sich des Herzogs Vertrauen in so hohem Masse zu erwerben, dass man ihn weder als Bibliothekar nach Hannover, weder an eine Universität oder ein Kollegium, noch 1789 als Landsyndikus wieder zur Landschaft liess, sondern ihn im Jahre 1790 zum Hofrath und noch in demselben Jahre zum Sekretär der geheimen Kanzlei ernannte. 1791 erhielt er Gärtners Kanonikat vom St. Blasiusdome, wodurch ihm pekuniärer Vorteil erwuchs. Sieben Jahre später wurde er Commissarius perpetuus bei dem allgemeinen Sterbe-Kassen-Institute, 1801 geheimer Justizrat und Referent mit Sitz und beratender Stimme im Geheimratskollegium, 1805 wurde ihm das Präsidium des Obersanitätskollegiums übertragen; es ist die Carrière eines pflichtgetreuen und weitblickenden Beamten. Litterarisch ist er fast nicht mehr thätig, dafür erwirbt er sich durch seine Reform des Braunschweigischen Armenwesens den Segen weit über das Grab hinaus.

Anfangs September 1806 befiel ihn eine hitzige Brustwassersucht, so dass er sein Ende voraussah; er sorgte für seine Frau, welcher er die Vernichtung seines handschriftlichen Nachlasses zur Pflicht machte. Am 10. September 1806 Morgens um halb sieben Uhr hatte sein menschenfreundliches Herz zu schlagen aufgehört; am 14. September wurde seine Leiche unter allgemeinster Teilnahme ins Grab versenkt, erst 27 Jahre später bettete man seine Sophie neben ihm zur Ruhe; sie war am 17. Dezember 1833 gestorben. 
Schlicht und einfach ist seine Erscheinung als Mensch und Schriftsteller, er blendet nicht, aber er gewinnt bei genauerer Bekanntschaft; er ist keine produktive Natur, aber sein inneres Leben ist tief und reich, seine Kenntnis ausgebreitet, sein Verstand klar und sein Witz rege. Hypochondrie, eine Folge seiner Kränklichkeit, hindert ihn an voller Anspannung seiner Kraft, und er ist ehrlich genug zu schweigen, da er nichts mehr zu verkünden hatte, er kommandiert die Poesie nicht, denn die Muse war ihm heilig. Achtung - mit diesem Worte bezeichnet man wohl am besten den Eindruck, welchen Leisewitz hervorrief.

Die vorliegende Ausgabe von Leisewitzens Julius von Tarent ist seit lange vorbereitet; nach dem Tode meines armen Freundes Gregor Kutschera Ritter von Aichbergen (21. April 1876), welcher ihn kurz vor Abschluss seiner Studienzeit traf, stellte mir sein Vater, Herr Hofrat F. Kutschera-Aichbergen, die Vorarbeiten, so weit sie sich auf die Ausgabe bezogen, zur Verfügung; sie bestanden in einer Abschrift des Originalmanuskriptes, welche faksimilierend genannt werden kann, und in einigen Vorschlägen über die Einrichtung einer Ausgabe. Ich bin ihnen nicht gefolgt, es erschien mir erspriesslicher, einen genauen Abdruck des Originalmanuskriptes vom Julius zu veranstalten, als eine kritische Ausgabe, denn gerade dadurch scheint mir der Wert meiner Ausgabe erhöht; es ist uns gegönnt, den Dichter bei der Arbeit $\mathrm{zu}$ belauschen, die allmählichen Veränderungen $\mathrm{zu}$ studieren, welche sich einstellen, zu sehen, wie ein Satz, welcher an der Einen Stelle gestrichen wurde, an einer andern wieder auftaucht. So gut sich dies durch den Druck veranschaulichen liess, ist es im folgenden geschehen; dabei unterliess ich auf Wunsch Seufferts die Siglen, welche ich nach dem Vorgange Goedekes durchgeführt hatte, denn es ist richtig, dass dadurch der 
Apparat zwar an Umfang, aber auch an Klarheit und Brauchbarkeit gewonnen habe.

Die Liebenswürdjgkeit des Braunschweigischen Stadtarchives ermöglichte mir die Benutzung der Handschrift auf unserer Universitätsbibliothek, eine genaue Kollation ergab zahlreiche Verbesserungen von Kutscheras Abschrift, zudem hat meine Beschäftigung mit Nicolais Nachlass meinen Blick geschärft, ich kounte vieles lesen, was Kutschera - er nahm die Abschrift mit einundzwanzig Jahren als Student - fraglich lassen musste; dies ist kein Verdienst, sondern notwendige Folge langjähriger Übung.

Ich habe im Apparate nur die Lesarten der beiden $1776 \mathrm{er}$ Ausgaben verzeichnet, die Gründe sind oben S. XXXII f. entwickelt. Ich kenne aber folgende Ausgaben (die mit ${ }^{*}$ bezeichneten waren Kutschera $\mathrm{S}$. 73 entgangen):

* 1) Leipzig $1776 O^{1}$. 2) Leipzig $1776 O^{2}$. 3) Meiningen 1780 mit der Angabe: 'Aufgef. am S. Meiningenschen Hofe'. *4) Stuttgard, in der Druckerey der Herzogl. Hohen Karls-Schule, 1784. *5) Augsburg 1791 (Deutsche Schaubühne Dritten Jahrgangs Achter Band). 6) Leipzig zweyte Auflage 1797. 7) 3. Aufl. 1816. 8) 4. Aufl. 1828. 9) Schriften, Wien 1816. 10) Sämmtliche Schriften. Braunschweig 1838. 11) Familienbibliothek deutscher Klassiker 9. Band. Hildburghausen und Amsterdam 1841. 12) Universalbibliothek Nr. 111 Leipzig Reclam o. J. [1870]. 13) Julius von Tarent u. a. poet. Schriften. Berlin, Ebeling und Plahe 1870. 14) Deutsche National-Litteratur 79. Band Stürmer und Dränger I bg. von Sauer Berlin und Stuttgart o. J. [1883]. Sauer.

Ich bezeichne mit $A$ das Originalmanuskript, 243 Seiten $4^{0}$, auf blauem Konzeptpapier mit breitem eingebogenen Rande geschrieben. (Paginiert von Schiller.)

Scenen in $A$. mit $B$ weggelegte Fassungen einzelner 
mit $O$ die übereinstimmende Lesart der beiden $1776 \mathrm{er}$ Ausgaben.

mit $O^{1}$ den getreueren, also älteren Abdruck bei Weygand in Leipzig 1776 (kgl. Bibliothek in Berlin Yr 6672).

mit $O^{2}$ den zweiten Abdruck bei Weygand in Leipzig 1776. Die übrigen Zeichen sind aus den kritischen Ausgaben bekannt. [] bedeutet Ergänzungen des Herausgebers, ] nach einer Lesart im Apparat, dass für die vor ] stehenden Worte die nach ] folgenden in $B$ oder $O$ gewählt seien. Ich habe die Seitenzahlen von $A$ im Texte in ( ), die Seitenzahlen von $O$ im Texte fett in [ ] angegeben.

Damit man Leisewitzens dramatische Thätigkeit überblicken könne, folgen dem Julius von Tarent die kleineren Scenen und Fragmente: 1) Die Pfandung. 2) Der Besuch um Mitternacht, beide aus dem Musenalmanach. 3) Konradin. 4) Alexander und Hephästion. 5) Selbstgespräch eines starken Geistes, alle drei aus Boies Deutschem Museum, endlich 6) Der Sylvesterabend, das Fragment des Lustspieles aus dem Nachlasse.

Das 'Selbstgespräch' nehme ich trotz der Einwendungen Kutscheras S. 99 f. Anm. für Leisewitz in Anspruch; einige Gründe finden sich in den Anmerkungen.

Bei meiner Arbeit erfreute ich mich liebenswürdiger Teilnahme, für welche ich meinen Dank auch hier ausspreche Herrn Hofrat Fr. Kutschera Ritter von Aichbergen, jetzt in Graz; Herrn Stadtarchivar Ludwig Hänselmann in Braunschweig für leihweise Übersendung des Originalmanuskriptes und der Briefe Leisewitzens an Sophie, der k. k. Universitätsbibliothek in Lemberg, der Kgl. Bibliothek in Berlin; dass auch Freund Seuffert seinen Rat spendete, habe ich bereits hervorgehoben. 
Ich weihe diesès Bändchen in treuer Anhänglichkeit meinem verewigten Freunde

\section{GREGOR KUTSCHERA,}

dessen Darstellung ich nur als Ährenleser folgen konnte; sein Buch erschien unter dem Titel: 'Johann Anton Leisewitz Ein Beitrag zur Geschichte der deutschen Literatur im XVIII. Jahrhundert von Gregor Kutschera v. Aichbergen Nach dem Tode des Verfassers herausgegeben [von Karl Tomaschek] Wien 1876.' Vereint mit ihm, an den ich mich innig angeschlossen hatte, gedachte ich durchs Leben zu gehen, es war anders bestimmt. Fiducit! 